\title{
Scope Definition of Air Force Design and Construction Projects
}

by

\author{
EVAN PENNER DICKS \\ B.S., Oklahoma State University, 2012
}

\author{
A thesis submitted to the \\ Faculty of the Graduate School of the \\ University of Colorado in partial fulfillment \\ of the requirement for the degree of \\ Master of Science
}

Department of Civil, Environmental, and Architectural Engineering

2016 
This thesis entitled:

\section{Scope Definition of Air Force Design and Construction Projects}

Written by: Evan Dicks

has been approved for the Department of Civil, Environmental, and Architectural Engineering

\begin{tabular}{c}
\hline Chair: Keith Molenaar \\
\hline Paul Goodrum \\
\hline Matthew Morris \\
\hline G. Edward Gibson, Jr. \\
\hline Date
\end{tabular}

Date

The final copy of this thesis has been examined by the signatories, and we find that both the content and the form meet acceptable presentation standards of scholarly work in the above mentioned discipline.

IRB protocol \# 16-0462 


\begin{abstract}
Dicks, Evan Penner (M.S., Civil, Environmental, and Architectural Engineering)

Scope Definition of Air Force Design and Construction Projects

Thesis directed by Professor Keith Molenaar and co-directed by Professors Paul Goodrum and Senior Instructor Matt Morris

Industry practitioners and researchers recognize project scope definition as a factor of project success in terms of cost and schedule. The Construction Industry Institute developed the Project Definition Rating Index (PDRI) as a tool to aid in project scope development. The Air Force has adopted use of this tool, though has yet to validate its effectiveness empirically. The objective of this study is to provide that empirical validation by comparing the cost, schedule, and budget estimate performance metrics of Air Force military construction (MILCON) projects that used the PDRI against those that did not. Project data for 263 (100 PDRI and 163 non-PDRI) MILCON projects worth $\$ 3.9$ Billion were analyzed. The projects that used the PDRI performed better on all three metrics, with statistically significant results on both cost and schedule growth. This study provides empirical evidence of how the use of formal scope definition tools can improve project performance.
\end{abstract}




\section{Acknowledgement}

I would like to thank several individuals who were essential to the success of this research. First, I want to thank my advisor, Dr. Keith Molenaar. He has been an incredible mentor in both the specifics of this research and the general research process. I would also like to thank the other two members of my committee, Dr. Paul Goodrum, and Professor Matthew Morris, for serving on the committee and providing direction and feedback on this thesis.

There have been a few members who generously gave their time to educate me on specific areas of expertise involved in this report. Dr. Edd Gibson has provided valuable guidance on project planning as a whole, and the PDRI specifically. Two members of the Air Force Civil Engineer Center, Mr. Ben Kindt, and Mr. Shannon Buckley, have been instrumental by providing me with information and contacts, and supporting this research at every step. I would also like to thank my fellow students for their input along the way, but specifically Lt Col Scott Stanford for tolerating my constant interruptions to answer my questions and help develop my research.

Finally, I would like to thank my friends and family for their support and encouragement during my graduate school tenure. I could not ask for a better group of people. 


\section{Table of Contents}

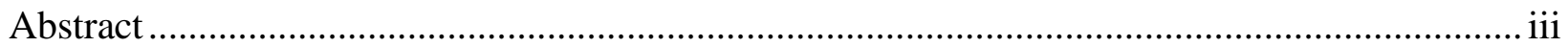

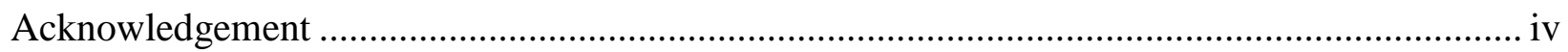

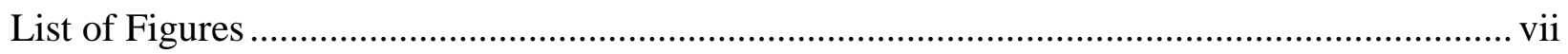

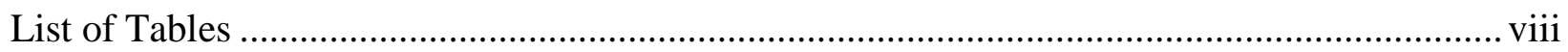

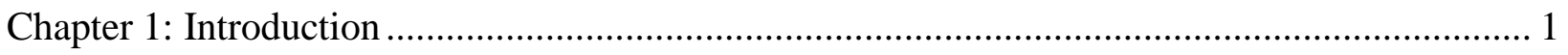

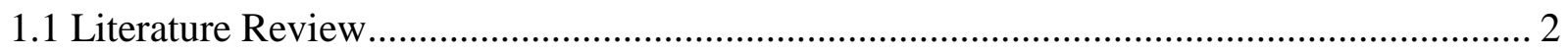

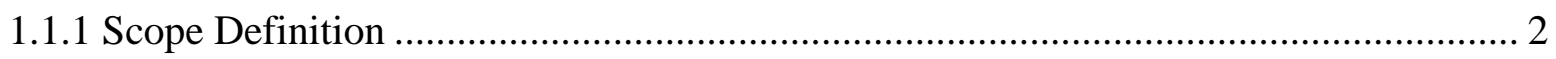

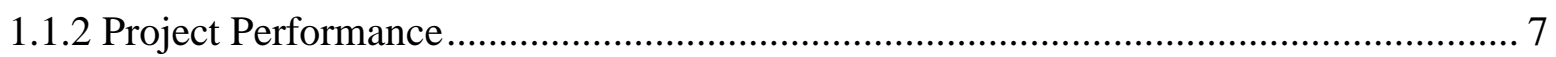

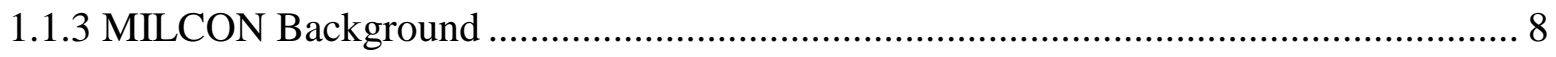

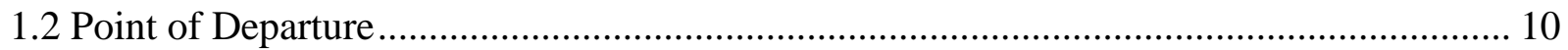

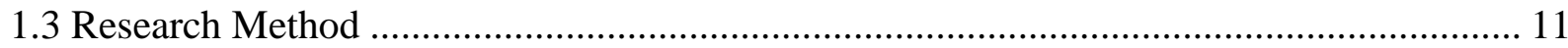

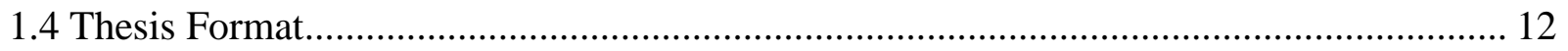

Chapter 2: Scope Definition of Air Force Design and Construction Projects .............................. 13

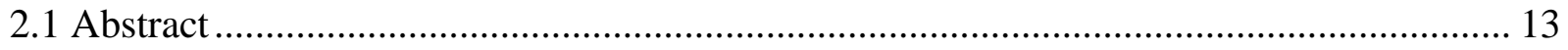

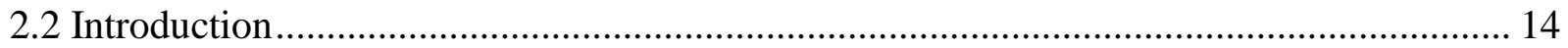

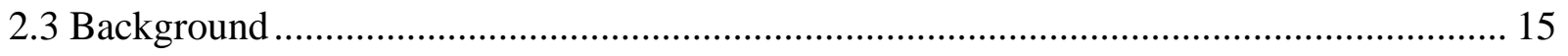

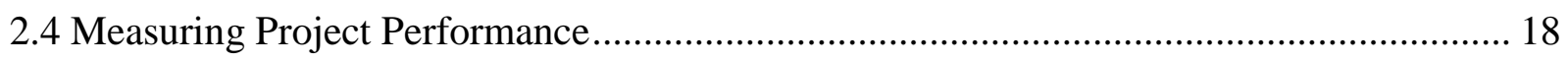

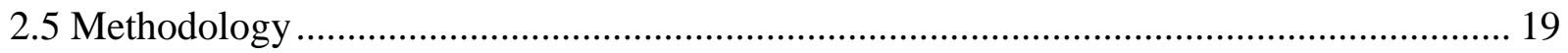

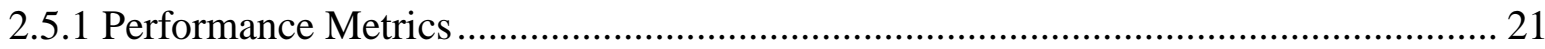




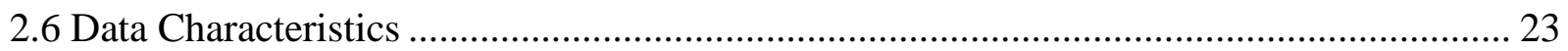

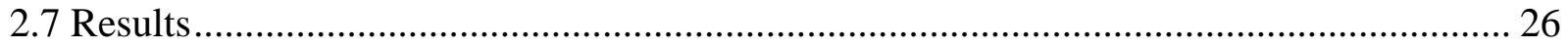

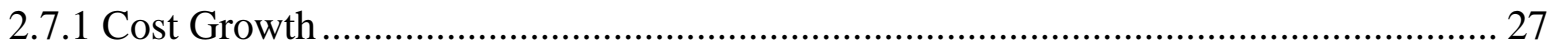

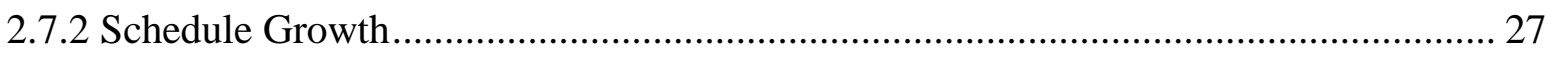

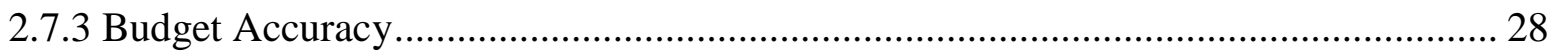

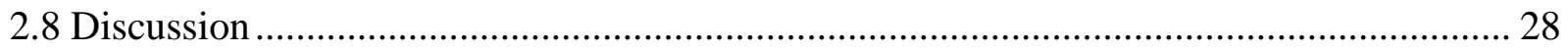

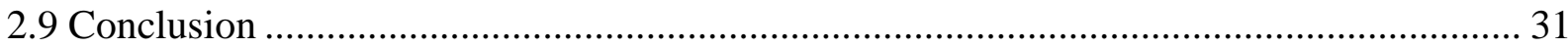

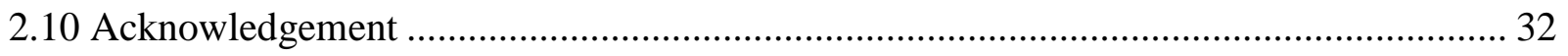

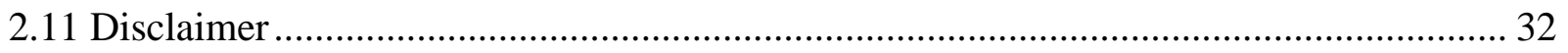

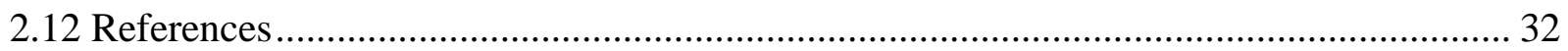

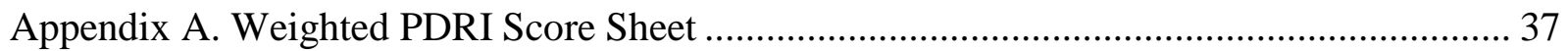

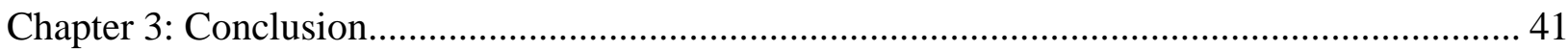

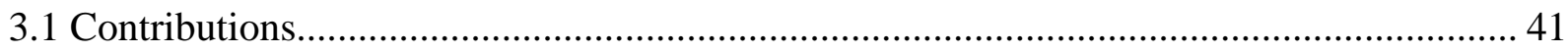

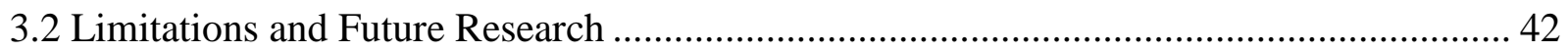

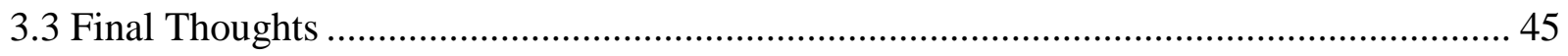

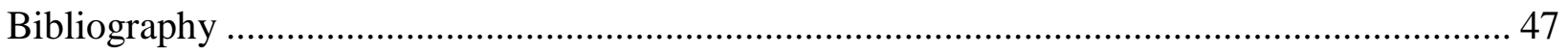




\section{List of Figures}

Figure 1. PDRI Sections, Categories, and Elements (Cho and Gibson 2001) ............................ 4

Figure 2. Example Element Description, A2. Business Justification ..................................... 5

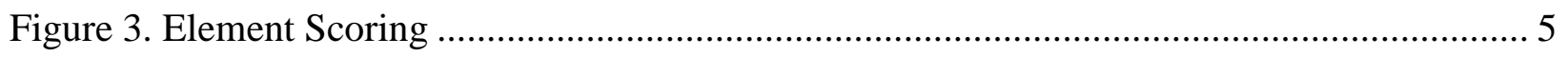

Figure 4. MILCON Timeline (adapted from Department of the Air Force 2013) ...................... 9

Figure 5. MILCON Timeline (adapted from Department of the Air Force 2013) ..................... 15

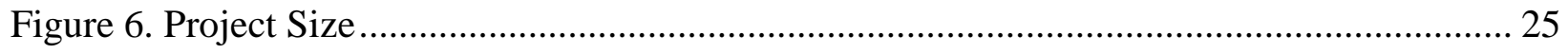

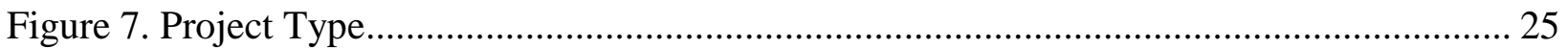




\section{List of Tables}

Table 1. Defining project performance ............................................................................. 7

Table 2. Authors linking project definition to performance ................................................. 19

Table 3. Influence of Project Characteristics ..................................................................... 24

Table 4. Delivery Method and Duration .............................................................................. 24

Table 5. Mean Performance Results .................................................................................. 26

Table 6. Variance Performance Results ................................................................................. 26 


\section{Chapter 1: Introduction}

As the United States (US) national debt approaches \$20 Trillion, the need for budget scrutiny becomes increasingly clear. Due to the large fiscal demand, Military Construction (MILCON) projects are an area in which leaders are actively pursuing solutions to maximize the benefit of public expenditure. The MILCON program received just over \$8 Billion in Fiscal Year 2016 (FY16), of which nearly \$1.4 Billion was directed to the Air Force MILCON program (114th Congress 2015). An analysis of 337 Air Force MILCON projects from 2000 to 2013 worth $\$ 4.1$ Billion showed an average cost growth of $6.4 \%$ with as high as $11.4 \%$ cost growth on the traditional design-bid-build projects with a design duration under 180 days (Stouter 2016). This is a clear demonstration of one performance issue, and the problem is not unique to the Department of Defense. Wang (2002) studied 78 building projects that showed an average cost growth of $10.6 \%$ and an average schedule growth of $16.9 \%$. Gibson et al. (2006a) later studied 108 building projects with an average cost growth of $7.9 \%$ and schedule growth of $17.5 \%$. Finally, Chen et al. (2015) found an average cost growth of $6.5 \%$ through a study of 254 public building projects using the design-build delivery method. It is clear that the construction industry as a whole faces performance challenges on building projects.

When projects miss their initial budget and schedule goals, they suffer not only from the direct effects, but also less quantifiable indirect effects. Chester and Hendrickson (2005) cite impacts such as legal claims arising from a mismanaged project, the sacrifice of safety or quality to accelerate a project behind schedule, and having a negative effect on the willingness, price, and quality of proposals on future projects. In an extreme scenario, a project may be completely abandoned or cancelled if the budget or schedule goals are not met (Mukuka et al. 2015). 
Cost, schedule, and scope make up what is often called the "iron triangle" in construction project management, suggesting that impacting one will inevitably affect the other two. The goal of project management is then finding the most effective combination of these three constraints to meet the project objectives; managers must actively make tradeoffs among them throughout the project cycle. Increased scope definition has emerged as a solution to improving cost and schedule performance. Based on this goal, and building on the progress of past research, the purpose of this thesis is to evaluate the effectiveness of using a formal scope definition tool during project planning.

\subsection{Literature Review}

\subsubsection{Scope Definition}

With the iron triangle of constraints in mind, one can see why scope definition is commonly highlighted as a fundamental aspect of construction project management. The level to which the project development teams define scope requirements has been widely linked as a key factor for project success (Songer and Molenaar 1997; Dumont et al. 1997; Chan et al. 2001; Cho and Gibson 2001; Song and AbouRizk 2005; Cho et al. 2009). These research efforts point out that poor or incomplete scope definition can lead to changes, delays, and rework that result in cost and schedule overruns, sometimes even leading to failure. Chritamara et al. (2001) explained the importance of initial scope establishment before engaging a design-build contractor. An empirical study by Xia et al. (2015) highlights a direct causal effect of project definition on performance in addition to an indirect effect through design quality, project communication, and alignment.

Front end planning has been studied through research efforts of the Construction Industry Institute (CII) beginning in 1991. One result of these efforts was the creation of the Project 
Definition Rating Index (PDRI). While the original PDRI was created for application on industrial projects, later iterations of the tool added building and infrastructure projects to its capabilities (Cho and Gibson 2000; Bingham 2010). The PDRI allows a project team to evaluate the completeness of scope definition prior to detailed design or construction (Dumont et al. 1997). Specifically, this is the point where the project team has the highest influence on changes to the project for the lowest cost.

The PDRI for buildings was developed to combat the frequent scope definition issues faced by building project managers. It helps project stakeholders quickly analyze the scope definition package and predict the factors that may impact project risk, specifically in regard to buildings (Cho and Gibson 2000). The Building PDRI was the result of a multi-step development process. First, the developers synthesized industry expert interviews with extensive literature examination to identify the list of elements. Second, they used multiple workshops involving input from experienced project managers, architects, and engineers with almost 1,500 total collective years of building project expertise to evaluate the relative importance and weight the PDRI elements (Cho and Gibson 2001). The final product consists of 64 elements grouped into 11 categories, and further grouped into three main sections, weighted by their importance to the completeness of project scope definition. The comprehensive list of elements are shown in Figure 1. 


\begin{tabular}{|c|c|}
\hline SECTION I. BASIS OF PROJECT DECISION & $\begin{array}{l}\text { E7. Functional Relationship Diagrams' } \\
\text { Room by Room }\end{array}$ \\
\hline A. Business Strategy & E8. Loading/Unloading/Storage Facilities \\
\hline Al. Building Use & Requirements \\
\hline A2. Business Justification & E9. Transportation Requirements \\
\hline A3. Business Plan & E10. Building Finishes \\
\hline A4. Economic Analysis & E11. Room Data Sheets \\
\hline A5, Facility Requirements & E12. Furnishings, Equipment, \& Built-Ins \\
\hline A6. Future Expansion/Alteration & E13. Window Treatment \\
\hline Considerations & F. Building/Project Design Parameters \\
\hline A7. Site Selection Considerations & F1. Civil/Site Design \\
\hline A8. Project Objectives Statement & F2. Architectural Design \\
\hline B. Owner Philosophies & F3. Structural Design \\
\hline B1. Reliability Philosophy & F4. Mechanical Design \\
\hline B2. Maintenance Philosophy & F5. Electrical Design \\
\hline B3. Operating Philosophy & F6. Building Life Safety Requirements \\
\hline B4. Design Philosophy & F7. Constructability Analysis \\
\hline C. Project Requirements & F8. Technological Sophistication \\
\hline $\mathrm{C1}$. Value-Analysis Process & G. Equipment \\
\hline C2. Project Design Criteria & G1. Equipment List \\
\hline C3. Evaluation of Existing Facilities & G2. Equipment Location Drawings \\
\hline C4. Scope of Work Overview & G3. Equipment Utility Requirements \\
\hline C5. Project Schedule & \\
\hline C6. Project Cost Estimate & SECTION III. EXECUTION APPROACH \\
\hline SECTION II. BASIS OF DESIGN & $\begin{array}{l}\text { H. Procurement Strategy } \\
\text { H1. Identify Long Lead/Critical }\end{array}$ \\
\hline D. Site Information & Equipment and Materials \\
\hline D1. Site Layout & H2. Procurement Procedures and Plans \\
\hline D2. Site Surveys & J. Deliverables \\
\hline D3. Civil/Geotechnical Information & J1. CADD/Model Requirements \\
\hline D4. Governing Regulatory Requirements & J2. Documentation/Deliverables \\
\hline D5. Environmental Assessment & K. Project Control \\
\hline D6. Utility Sources with Supply Conditions & K1. Project Quality Assurance and Control \\
\hline D7. Site Life Safety Considerations & K2. Project Cost Control \\
\hline D8. Special Water and Waste Treatment & K3. Project Schedule Control \\
\hline Requirements & K4. Risk Management \\
\hline E. Building Programming & K5. Safety Procedures \\
\hline E1. Program Statement & L. Project Execution Plan \\
\hline E2. Building Summary Space List & L1. Project Organization \\
\hline E3. Overall Adjacency Diagrams & L2. Owner Approval Requirements \\
\hline E4. Stacking Diagrams & L3. Project Delivery Method \\
\hline E5. Growth and Phased Development & L4. Design/Construction Plan \& Approach \\
\hline $\begin{array}{l}\text { E6. Circulation and Open Space } \\
\text { Requirements }\end{array}$ & L5. Substantial Completion Requirements \\
\hline
\end{tabular}

Figure 1. PDRI Sections, Categories, and Elements (Cho and Gibson 2001)

In addition to the simplified scoresheet, the PDRI contains detailed descriptions of each element and instructions for scoring a project. The detailed descriptions highlight the important 
aspects of the element and provides suggestions for items that deserve consideration. An

example element description is shown in Figure 2.

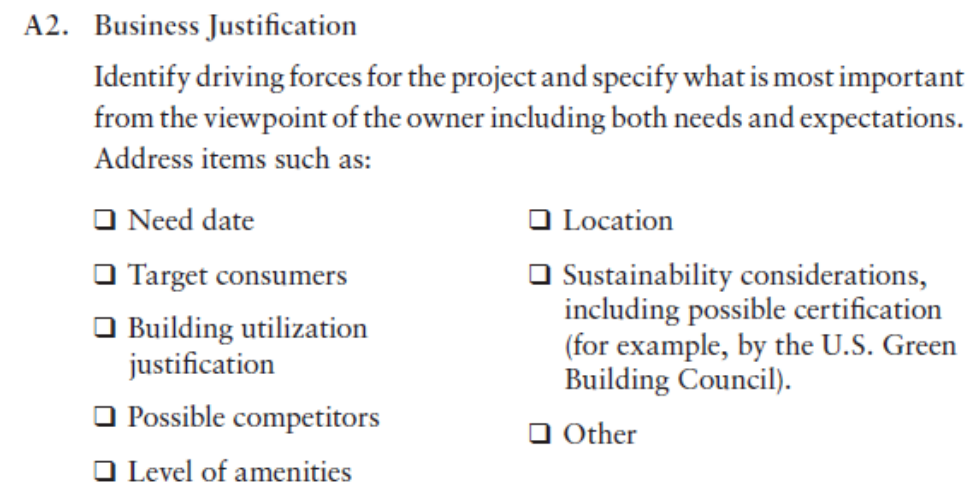

Additional items to consider for Renovation \& Revamp projects

Modification to building or infrastructure to meet existing or anticipated regulatory requirements

Figure 2. Example Element Description, A2. Business Justification

Each element is scored on a scale from 1 to 5 based on their level of definition, or given a "0" if the element does not apply to the particular project. The scoring procedure is illustrated in Figure 3. In the figure, "Phase Gate 3" corresponds to the beginning of the design stage of the project.

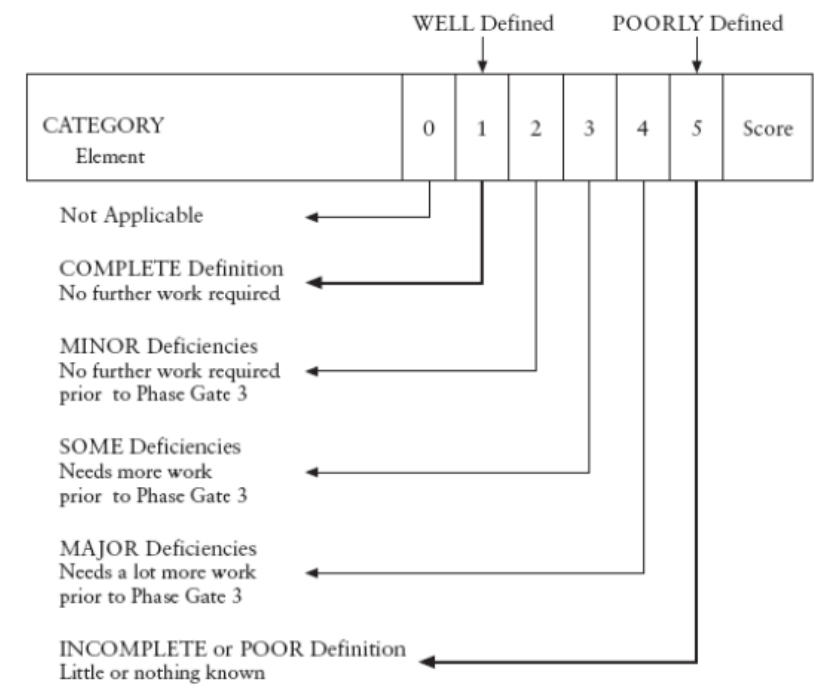

Figure 3. Element Scoring

Once every element is scored, the overall project score is determined by adding the weighted scores. In this way, the tool can directly assess the overall scope definition level on a given 
project; a higher score indicates poor definition and higher risk, while a lower score indicates better definition and lower risk.

The PDRI for buildings was then validated through 33 projects selected non-randomly and scored "after-the-fact." The results showed a significant difference between projects with lower PDRI scores (better level of scope definition) and projects with higher PDRI scores in terms of cost, schedule, and change order performance. While the performance results focused on the benefit of better scope definition in general, the team also conducted observations to assess the effectiveness of the PDRI on current projects. Cho and Gibson (2001) summarized the following observations:

- The PDRI can be used effectively more than once during project planning.

- The tool provides an excellent mechanism to identify specific problems and assign actions.

- Using the tool is an excellent way to align a project team.

- The PDRI is effective even when used very early in the planning process. Individual planners can use the tool at this point to identify potential problems and to organize their work effort.

- A facilitator provides a neutral party to help maintain consistency when scoring projects.

- The team or individual scoring the project should focus on the scoring process, rather than the final score, in order to honestly identify deficiencies.

While the PDRI can effectively measure the level of definition, the above observations suggest that the true benefit of the tool is in the facilitation process. After using the PDRI, a project team will understand the project challenges and risk areas, allowing them to develop and implement corrective procedures. Because of the success of this tool in industry, the Air Force 
adopted its use beginning in 2008 by updating the Air Force Instruction for MILCON projects. Use was later mandated through the planning and design instructions issued by the Air Force Civil Engineer Center that authorize those respective phases of the project.

\subsubsection{Project Performance}

Each construction project is unique, involving different stakeholders, limitations, and objectives. As a result, it is difficult to apply the same success criteria among a vast set of projects. Researchers have varied in how they define and measure project success, but Atkinson (1999) summarizes that cost, time, and quality have led performance measurement in project management over the last 50 years. Table 2 shows authors that have linked project definition to performance.

Table 1. Defining project performance

\begin{tabular}{|c|c|c|c|c|c|}
\hline \multirow[t]{2}{*}{ Author } & \multirow[t]{2}{*}{ Schedule } & \multirow[t]{2}{*}{ Cost } & \multicolumn{3}{|c|}{ Cost Definition } \\
\hline & & & $\begin{array}{c}\text { Final - } \\
\text { Estimate }\end{array}$ & $\begin{array}{c}\text { Final - } \\
\text { Contract }\end{array}$ & Predictability \\
\hline Dumont et al. 1997 & $\mathbf{X}$ & $\mathbf{X}$ & $\mathbf{x}$ & & \\
\hline Songer and Molenaar 1997 & $\mathbf{X}$ & $\mathbf{X}$ & & $\mathbf{x}$ & \\
\hline Cho and Gibson 2000 & $\mathbf{X}$ & $\mathbf{X}$ & $\mathbf{x}$ & & \\
\hline Griffith and Gibson 2001 & $\mathbf{X}$ & $\mathbf{X}$ & & & $\mathbf{x}$ \\
\hline Chritamara et al. 2001 & $\mathbf{X}$ & $\mathbf{X}$ & & $\mathbf{x}$ & $\mathbf{x}$ \\
\hline Wang 2002 & $\mathbf{X}$ & $\mathbf{X}$ & $\mathbf{x}$ & & \\
\hline Gibson et al. 2006 & $\mathbf{X}$ & $\mathbf{X}$ & $\mathbf{x}$ & & \\
\hline Atkinson et al. 2006 & $\mathbf{X}$ & $\mathbf{X}$ & & $\mathbf{x}$ & \\
\hline Le et al. 2009 & $\mathbf{X}$ & $\mathbf{X}$ & & $\mathbf{x}$ & \\
\hline Cho et al. 2009 & $\mathbf{X}$ & $\mathbf{X}$ & & $\mathbf{x}$ & $\mathbf{x}$ \\
\hline Bingham 2010 & $\mathbf{X}$ & $\mathbf{X}$ & $\mathbf{x}$ & & $\mathbf{x}$ \\
\hline Fageha et al. 2014 & $\mathbf{X}$ & $\mathbf{X}$ & & $\mathbf{x}$ & \\
\hline Rosenfeld 2014 & $\mathbf{X}$ & $\mathbf{X}$ & & $\mathbf{x}$ & \\
\hline Xia et al. 2015 & $\mathbf{X}$ & $\mathbf{X}$ & $\mathbf{x}$ & & \\
\hline
\end{tabular}

These authors all describe that both schedule and cost are key metrics for determining project success. Dumont et al. (1997), Cho and Gibson (2000), Wang (2002), and Bingham (2010) all 
studied the PDRI directly. These four authors cited benefits to project performance, measuring cost growth as the difference between the final project cost and the engineer's estimate, schedule growth, and the cost of change orders as a percentage of the project budget. Seven authors measured cost growth as the difference between the final project cost and the amount specified in the contract. Four authors identified that increased scope definition can lead to enhanced predictability of the budget. Additionally, these authors described benefits to the quality of the project, but due to data availability and time limitations, quality performance metrics are outside the scope of this research.

Measuring project performance in the Air Force in particular has evolved over the years, resulting in the current "Ribbon Cutter" criteria, which measure design, award, construction, and closure performance for the project. The construction performance category consists primarily of cost and schedule growth.

\subsubsection{MILCON Background}

To understand this research, the MILCON process must first be explained. Title 10, United States (U.S.) Code, Section 2801, defines military construction as "development, conversion, or extension of any kind carried out with respect to a military installation. MILCON includes construction projects for all types of buildings, roads, airfield pavements, and utility systems costing $\$ 750,000$ or more” (Department of the Air Force 2014). The program subdivides this process into planning, programming, design, and construction phases, and typically executes these projects over three to five years, see Figure 4. 


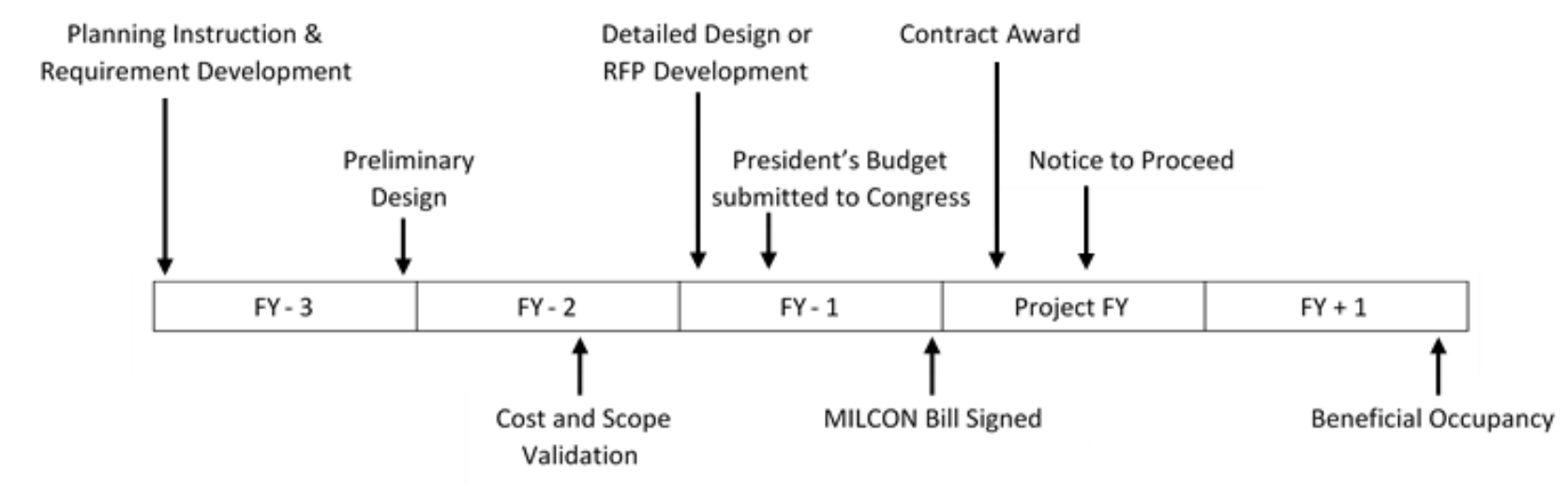

Figure 4. MILCON Timeline (adapted from Department of the Air Force 2013)

The planning and programming phases take place at the installation or base level. Installations identify facility needs 3-5 years in the future and determine which needs cannot be met with existing facilities. Installation commanders then review, validate, and prioritize MILCON facility requirements (Department of the Air Force 2014). The output of the MILCON planning and programming process is the Department of Defense form 1391 (DD 1391) Military Construction Project Data. “The DD 1391, by itself, shall explain and justify the project to all levels of the AF, Office of the Secretary of Defense (OSD), Office of Management and Budget, and Congress. Justification data shall clearly describe the impact on mission, people, productivity, life-cycle cost, etc., if the project is not accomplished" (Department of the Air Force 2014). During these phases and included in the DD 1391, the installations produce cost estimates and define the scope of the project. The project then competes among different submissions across the Air Force, and once it is approved, it is submitted to congress, and signed into law in the president's budget. It should be noted that not all submitted projects are approved, and that projects are submitted to the OSD before detailed design begins, meaning that the project is at most $35 \%$ designed prior to submission. 
The design and construction phases are then managed by the Air Force Civil Engineer Center (AFCEC). Progress and performance are tracked through the Automated Civil Engineering System-Project Management (ACES-PM). The design for the project converts the requirements identified in the previous phases into a usable facility. Both design-build and design-bid-build delivery methods can be used, and projects are typically tracked to one of these during the preliminary design stage. Design-build projects then prepare a Request for Proposal to guide bid submissions, while design-bid-build projects complete the detailed design on which construction firms will bid. After the project scope and budget have been approved, there are tight restrictions on changing the scope to align with the budget. For this reason, detail and accuracy in the early stages of the project are crucial to the success of the project in the construction phase.

\subsection{Point of Departure}

Previous research has thoroughly demonstrated the link between project definition and project performance. Collaborative efforts from academics and industry practitioners have created tools like the PDRI to aid in effective scope development, and observed the benefits of these tools on project planning. Despite the amount of ground covered by previous research, several gaps emerge. Perhaps due to a lack of projects sets that can be compared directly, there are no studies comparing the performance of projects that have used the PDRI against projects that have not. Additionally, little research has been conducted on military projects in this area. Finally, the studies analyzing performance as a product of PDRI score used "after the fact" scores, where managers rated the definition of the project scope after completion, possibly introducing biases from recollection ability and how well the project performed (Dumont et al. 1997, Cho and Gibson 2001, Wang 2002). No study has measured the impact of this tool from 
implementation at the planning stage. This paper will address these gaps by answering the following question:

- How does the implementation of a formal scope definition tool impact project performance in terms of cost growth, schedule growth, and the ability to accurately estimate the budget?

\subsection{Research Method}

When a study seeks to examine a relationship between variables, empirical research is the most appropriate method, and the approach is considered to be the most powerful support for a given hypothesis (Kothari 2004). The empirical approach requires data-based observations of the variables that can answer the research question. In this study, the aim is to examine the relationship between using a formal scope definition tool and the performance of a project by comparing performance data in an existing military construction project database. As a result, individual projects are the units of analysis for this research.

To answer the question posed for this research as accurately as possible, projects were considered for analysis only if they were (1) located in the US, including Alaska and Hawaii, and (2) executed from FY09 to FY14. Data was collected from two different sources: The Air Force ACES-PM system, and the US Army Corps of Engineers (USACE) PDRI website. ACES-PM is the primary system of record for Air Force construction projects and tracks over 100 unique fields of project data. The PDRI website is maintained by the Corps, but tracks PDRI progress and results across all military branches and all three execution agencies. The data from ACESPM was pulled on 19 April 2016 and consisted of 263 projects meeting the stated selection criteria. The data from the PDRI website was accessed on 27 August 2016 and consisted of 100 
projects meeting the stated selection criteria. The project data was analyzed using the appropriate statistical tests.

\subsection{Thesis Format}

This thesis follows the "journal paper" format. Chapter 2 is a stand-alone paper that will be submitted to an academic journal. As a result, the chapter has its own abstract, introduction, background, methodology, results, discussion, and conclusion sections. In this format, there will inevitably be some degree of overlap. The final chapter in this thesis discusses the research contributions, limitations, and potential future research. 


\section{Chapter 2: Scope Definition of Air Force Design and Construction Projects}

\subsection{Abstract}

Industry practitioners and researchers recognize project scope definition as a factor of project success in terms of cost and schedule. The Construction Industry Institute developed the Project Definition Rating Index (PDRI) as a tool to aid in the effectiveness of scope development. The Air Force has adopted use of this tool, though has yet to validate its effectiveness empirically. The objective of this study is to provide that empirical validation by comparing the cost, schedule, and budget estimate performance metrics of Air Force military construction (MILCON) projects that used the PDRI against those that did not. Project data for 263 (100 PDRI and 163 non-PDRI) MILCON projects were analyzed. The projects that used the PDRI performed better on all three metrics, with statistically significant results on both cost and schedule growth. This study provides empirical evidence of how the use of formal scope definition tools can improve performance for Air Force MILCON projects. When compared to previous research, the study also contributes to a broader understanding of scope definition in the design and construction industry. 


\subsection{Introduction}

As the United States (US) national debt approaches \$20 Trillion, the need for budget scrutiny becomes increasingly clear. Due to the large fiscal demand, Military Construction (MILCON) projects are an area in which leaders are actively pursuing solutions to maximize the benefit of public expenditure. The MILCON program received just over \$8 Billion in Fiscal Year 2016 (FY16), of which nearly \$1.4 Billion was directed to the Air Force MILCON program (114th Congress 2015). An analysis of 337 Air Force MILCON projects from 2000 to 2013 worth $\$ 4.1$ Billion showed an average cost growth of $6.4 \%$ with as high as $11.4 \%$ cost growth on the traditional design-bid-build projects with a design duration under 180 days (Stouter 2016). This is a clear demonstration of one performance issue, and the problem is not unique to the Department of Defense. Wang (2002) studied 78 building projects that showed an average cost growth of $10.6 \%$ and an average schedule growth of $16.9 \%$. Gibson et al. (2006a) later studied 108 building projects with an average cost growth of $7.9 \%$ and schedule growth of $17.5 \%$. Finally, Chen et al. (2015) found an average cost growth of $6.5 \%$ through a study of 254 public building projects using the design-build delivery method.

When projects miss their initial budget and schedule goals, they suffer not only from the direct effects, but also less quantifiable indirect effects. Chester and Hendrickson (2005) cite impacts such as legal claims arising from a mismanaged project, the sacrifice of safety or quality to accelerate a project behind schedule, and having a negative effect on the willingness, price, and quality of proposals on future projects. In an extreme scenario, a project may be completely abandoned or cancelled if the budget or schedule goals are not met (Mukuka et al. 2015). Increased scope definition has emerged as a potential solution to improving cost performance, among other metrics. 
This is the first study analyzing the effectiveness of planning tools that were used in real time and one of the largest studies on projects using the Project Definition Rating Index (PDRI) to date. Further, this study benefits from the use of a controlled database where projects are all developed under a standardized process and executed in a similar manner. Previous scope definition research has suffered from a lack of available projects and an "after-the-fact" implementation of planning tools that measures the level of scope definition rather than the direct benefit of the tools themselves. As a means to add to the current body of knowledge, this research seeks to empirically discover the effectiveness of the PDRI on Air Force MILCON projects by comparing the performance metrics of those that used a formal scope definition tool prior to construction with those that did not.

\subsection{Background}

The MILCON program provides a structure to manage new facility, major renovation, and repair projects costing $\$ 750,000$ or more (Department of the Air Force 2014). The program subdivides this process into planning, programming, design, and construction phases, and typically executes these projects over three to five years, see Figure 5.

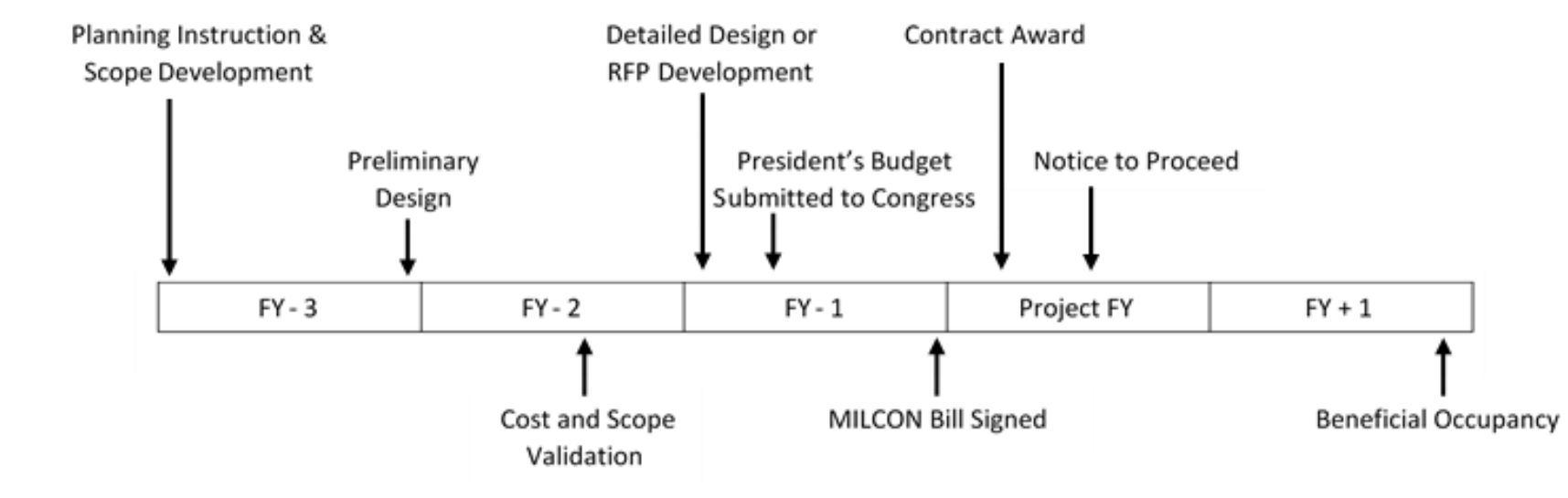

Figure 5. MILCON Timeline (adapted from Department of the Air Force 2013) 
The planning and programming phases develop the requirements into a usable facility and complete the initial cost estimate. The initial project submission takes place shortly after the cost and scope validation, between the preliminary and detailed design stages. With the initial scope development and cost estimates taking place early in the project timeline, and because of the restrictions governing scope and budget modifications after approval, the importance of thoroughness and rigor on these processes is evident.

The level to which the project development teams define scope requirements has been widely linked as a key factor for project success (Songer and Molenaar 1997; Dumont et al. 1997; Chan et al. 2001; Cho and Gibson 2001; Song and AbouRizk 2005; Cho et al. 2009). These research efforts point out that poor or incomplete scope definition can lead to changes, delays, and rework that result in cost and schedule overruns, sometimes even leading to failure. Chritamara et al. (2001) explained the importance of initial scope establishment before engaging a design-build contractor. An empirical study by Xia et al. (2015) highlights a direct causal effect of project definition on performance in addition to an indirect effect through design quality, project communication, and alignment.

Front end planning has been studied through research efforts of the Construction Industry Institute (CII) beginning in 1991. One result of these efforts was the creation of the Project Definition Rating Index (PDRI). While the original PDRI was created for application on industrial projects, later iterations of the tool added building and infrastructure projects to its capabilities (Cho and Gibson 2000; Bingham 2010). The PDRI allows a project team to evaluate the completeness of scope definition prior to detailed design or construction (Dumont et al. 1997). Specifically, this is the point where the project team has the highest influence on changes to the project for little cost. 
The PDRI for Buildings was developed to combat the frequent scope definition issues faced by building project managers. It helps project stakeholders quickly analyze the scope definition package and predict the factors that may impact project risk, specifically in regard to buildings (Cho and Gibson 2000). The Building PDRI was the result of a multi-step development process. First, the developers synthesized industry expert interviews with extensive literature examination to identify the list of elements. Second, they used multiple workshops involving input from experienced project managers, architects, and engineers with almost 1,500 total collective years of building project expertise to evaluate the relative importance and weight the PDRI elements (Cho and Gibson 2001). The final product consists of 64 elements grouped into 11 categories, and further grouped into three main sections, weighted by their importance to the completeness of project scope definition. The weighted scoresheet is shown in Appendix A.

In addition to the scoresheet, the PDRI contains detailed descriptions of each element and instructions for scoring a project. The CII team then validated the tool through 33 projects selected non-randomly and scored "after-the-fact." The results showed a significant difference between projects with lower PDRI scores (better level of scope definition) and projects with higher PDRI scores in terms of cost, schedule, and change order performance. While the performance results focused on the benefit of better scope definition in general, the team also conducted observations to assess the effectiveness of the PDRI on current projects. Cho and Gibson (2001) summarized the following observations:

- The PDRI can be used effectively more than once during project planning.

- The tool provides an excellent mechanism to identify specific problems and assign actions.

- Using the tool is an excellent way to align a project team. 
- The PDRI is effective even when used very early in the planning process. Individual planners can use the tool at this point to identify potential problems and to organize their work effort.

- A facilitator provides a neutral party to help maintain consistency when scoring projects.

- The team or individual scoring the project should focus on the scoring process, rather than the final score, in order to honestly identify deficiencies.

While the PDRI can effectively measure the level of definition, the above observations suggest that the true benefit of the tool is in the facilitation process. After using the PDRI, a project team will understand the project challenges and risk areas, allowing them to develop and implement corrective procedures. Because of the success of this tool in industry, the Air Force adopted its use beginning in 2008 by updating the Air Force Instruction for MILCON projects. Use was later mandated through the planning and design instructions issued by the Air Force Civil Engineer Center that authorize those respective phases of the project.

\subsection{Measuring Project Performance}

Each construction project is unique, involving different stakeholders, limitations, and objectives. As a result, it is difficult to apply the same success criteria among a vast set of projects. Researchers have varied in how they define and measure project success, but Atkinson (1999) summarizes that cost, time, and quality have led performance measurement in project management over the last 50 years. The Air Force has established performance criteria of their own, including cost growth, schedule growth, and award ratio. Table 2 shows authors that have linked project definition to performance. These authors all describe that both schedule and cost are key metrics for determining project success. 
Table 2. Authors linking project definition to performance

\begin{tabular}{lll} 
& \multicolumn{1}{c}{ Cost Performance Definition } & \\
\hline \multicolumn{1}{c}{ Final - Estimate } & \multicolumn{1}{c}{ Final - Contract } & \multicolumn{1}{c}{ Predictability } \\
\hline Dumont et al. 1997* & Songer and Molenaar 1997* & Griffith and Gibson 2001 \\
Cho and Gibson 2000 & Chritamara et al. 2001 & Chritamara et al. 2001 \\
Chan et al. 2001* & Atkinson et al. 2006* & Cho et al. 2009 \\
Wang 2002 & Le et al. 2009 & Bingham 2010 \\
Gibson et al. 2006* & Cho et al. 2009 & \\
Bingham 2010 & Fageha et al. 2014 & \\
Xia et al. 2015 & Rosenfeld 2014 & \\
\hline
\end{tabular}

*Indicates more than 75 citations

The table indicates that the measurement of cost performance varies to some degree, which can be attributed to available information at the time of the studies and the different objectives of the studies themselves. Schedule performance is measured by comparing the actual duration to the planned duration. Additionally, these authors described benefits to the quality of the project, but due to data availability and time limitations, quality performance metrics are outside the scope of this research.

\subsection{Methodology}

When a study seeks to examine a relationship between variables, empirical research is the most appropriate method, and the approach is considered to be the most powerful support for a given hypothesis (Kothari 2004). The empirical approach requires data-based observations of the variables that can answer the research question. In this study, we aim to examine the relationship between using a formal scope definition tool and the performance of a project by comparing performance data in an existing military construction project database.

There are several advantages to performing a study on this particular data set. First, military construction projects are a well-documented and reliable data source due to process consistency and Congressional oversight (Rosner et al. 2009). Second, performance data is 
managed in a central database where projects can be easily compared. Finally, because of the process consistency and similarities in project development, variables can be controlled more easily, leading to enhanced clarity in the results.

Overall performance data and project characteristics were collected from the Automated Civil Engineering System-Project Management (ACES-PM) database on 19 April 2016. ACESPM is the primary system of record for Air Force construction projects. It is updated by project managers and maintained by the Air Force Civil Engineer Center. PDRI results were collected from the US Army Corps of Engineers. The Corps of Engineers is the largest of three executing agencies in the MILCON program. The agency maintains the PDRI database for the entire Department of Defense, so that every MILCON project using the PDRI is tracked in the same location.

Despite the advantages, there are some limitations concerning the accuracy and thoroughness of the data in ACES-PM. Some of the projects within the database were missing data or clearly inaccurate upon review, such as a negative duration. These were omitted from the analysis and results. Although this was rare, it suggests that the data in the system is not flawless or immune to human error. Extreme outliers were identified in the data set using the statistical software MVPstats that defines an outlier as "extreme" if it is more than 3 times the interquartile range above the third quartile or below the first quartile (MVP Programs 2014). These outliers were examined to determine whether the data was simply entered incorrectly or if the project actually experienced extreme performance differences. Extreme outliers were removed from the data set as they were either anomalies or the result of entry errors. The resulting data set was 263 projects (100 that used the PDRI and 163 that did not) representing \$3.9 Billion in cost. 
For projects that used the PDRI, there are three "gates" along the project timeline that project team facilitates a PDRI: Planning, Design, and Ready to Advertise. Referring back to Figure 5, the Planning gate occurs during the initial planning instruction, and the Design gate occurs at the preliminary design stage. The Ready to Advertise gate does not occur until after the project budget has been submitted to Congress. Therefore, projects that facilitated a PDRI only at the Ready to Advertise gate were omitted from the data set for the budget accuracy comparison because the benefit of using the tool would not be captured in this metric (i.e. the budget on which we are measuring accuracy was submitted before the team facilitated a PDRI).

\subsubsection{Performance Metrics}

To maintain consistency with previous research efforts, and because of the stated MILCON project management goals, we selected cost growth, schedule growth, and budget accuracy as the metrics to evaluate the project performance. The metrics are defined and discusses in the following paragraphs.

The cost growth calculation comes directly from the process used by the Air Force for assessment. It is a direct ratio of the actual cost of the project to what was specified in the construction contract. This study models cost growth in the equation

$$
\text { Cost Growth }(\%)=\left[\left(\frac{\text { Actual Project Cost }}{\text { Original Contract Amount }}\right)-1\right] \times 100
$$

where the Actual Project Cost is the sum of modifications to the contract and the original contract amount, and the Original Contract Amount was the winning bid (or proposal) and contract price. The Air Force currently tracks modifications using nine different "reason codes" ranging from a user-requested change to an error/omission in the requirements. A detailed look at contract modifications was not included in this study. 
Schedule growth is used to describe the relationship between planned completion and actual completion. The equation used to calculate schedule growth is

$$
\text { Schedule Growth }(\%)=\left[\left(\frac{\text { Actual Project Duration }}{\text { Contract Duration }}\right)-1\right] \times 100
$$

where Actual Project Duration is calculated as the difference between the date that the contractor had completed enough of the work for the end user to move in and begin operating (Beneficial Occupancy Date) and the date that the contractor was issued a notice to proceed indicating that work can begin, and Contract Duration was the time allotted for construction specified in the contract.

Budget accuracy was determined by isolating the amount dedicated for construction in the programmed amount approved by Congress (shown as the President's budget submission in Figure 5), and comparing it to the awarded contract. We used the equation

$$
\text { Budget Accuracy }(\%)=\frac{\mid \text { Original Contract Amount }- \text { Construction Budget } \mid}{\text { Construction Budget }} \times 100
$$

where the Construction Budget is the portion of the total approved budget dedicated for construction. While awarding a contract under the budget is better than exceeding the budget, the ideal scenario is to spend as close to the amount budgeted as possible, therefore, the accuracy was determined by the absolute value of the difference between the contract amount and the construction budget rather than simply the difference. If projects are consistently over-budgeted (i.e., the budgeted amount consistently exceeds the bids), then projects are not being awarded in an efficient manner, leading to a gap between the amount of projects that could have been constructed from the funds available and the amount of projects that were actually built. Conversely, under-budgeted projects require additional funds, which must also be approved by Congress. This process causes an administrative burden while delaying the project completion. 
The calculated Construction Budget does not include standard contingency (5\%) and the supervision costs (5.7\% for Continental US; $6.5 \%$ for Alaska/Hawaii) as these percentages are not represented in the project bid or proposal. Design-build projects also include a $4 \%$ design fee, but this was not factored into the calculation since that fee is included in the contractor's price proposal.

To analyze the data, the performance metrics were compared by testing the following hypothesis:

\section{$\mathrm{H}_{\mathrm{o}}$ : the average performance of the projects using PDRI will be worse than or equal to the average performance of projects that did not use the PDRI. \\ $\mathrm{H}_{\mathrm{a}}$ : the average performance of the projects using PDRI will be significantly better than those that did not use PDRI.}

Testing the groups for statistical significance required first testing the variances to determine the appropriate test for means. A $t$ test was appropriate in this case because the projects within both groups are independent of each other, and both groups were independent of one another (Ramsey and Schafer 2012). This statistical test often assumes that the populations are normally distributed, but the test is robust to this assumption if the number of projects is sufficiently large, as is the case for this study (Ramsey and Schafer 2012). Using a one-tailed test statistic, $p$ values less than 0.05 were considered statistically significant, and $p$ values less than 0.01 were considered highly significant.

\subsection{Data Characteristics}

For this research, projects were considered for analysis only if they were (1) located in the US, including Alaska and Hawaii, and (2) executed from FY09 to FY14. To meet the objective of this study, analysis was conducted to identify differences between the two groups 
that might influence the results. We compared delivery method, facility type, size in terms of cost, and project duration between both groups. These four characteristics are often compared to identify other sources of influence on project performance; see Table 3.

Table 3. Influence of Project Characteristics

\begin{tabular}{lc}
\hline \multicolumn{1}{c}{ Characteristic } & Study \\
\cline { 1 - 1 } $\begin{array}{l}\text { Delivery Method } \\
\text { Facility Type }\end{array}$ & Rosner et al. (2009), Hale et al. (2009) \\
Size (\$) & Beach (2008), Cho et al. (2009) \\
Duration & Cho et al. (2009), Gibson and Bosfield (2012) \\
\hline
\end{tabular}

Table 4 shows a breakdown of projects for each group in the delivery method and duration subcategories. Rosner et al. (2009) showed that the delivery method has a significant impact on Air Force MILCON cost growth with design-build projects outperforming design-bid-build projects $4.5 \%$ to $6.4 \%$, respectively. The projects using the PDRI had two percent more design-build projects, and four percent more projects taking less than 650 days to complete. These differences were not significant, and therefore considered negligible.

Table 4. Delivery Method and Duration

\begin{tabular}{|c|c|c|c|c|c|c|}
\hline \multirow[b]{2}{*}{ Group } & \multicolumn{2}{|c|}{ Delivery Method } & \multicolumn{4}{|c|}{ Duration (Days) } \\
\hline & DB & DBB & $<365$ & $365-649$ & $650-999$ & $\geq 1000$ \\
\hline PDRI $(n=100)$ & $70 \%$ & $30 \%$ & $5 \%$ & $51 \%$ & $34 \%$ & $10 \%$ \\
\hline Non-PDRI (n=163) & $68 \%$ & $32 \%$ & $4 \%$ & $48 \%$ & $38 \%$ & $10 \%$ \\
\hline
\end{tabular}

Figure 6 compares the projects by size. The PDRI group had five percent more projects costing less than $\$ 5$ Million, but the differences again were not significant, and considered negligible. 


\section{Programmed Amount (\$M)}

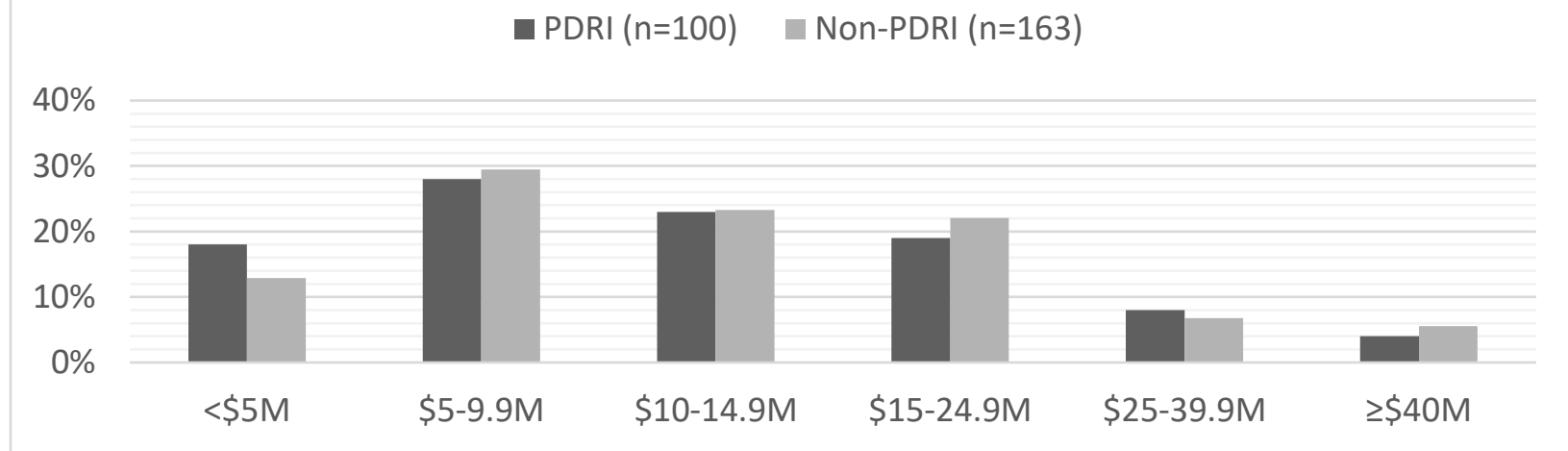

Figure 6. Project Size

Figure 7 shows the project distribution by facility type, where there are a few differences between the groups. Beach (2008) showed the effect of facility type on MILCON projects:

Airfield Pavement projects have a significantly higher cost performance (less cost growth), while Personnel Support and Morale, Welfare, and Recreation projects have significantly lower cost performance (more cost growth).

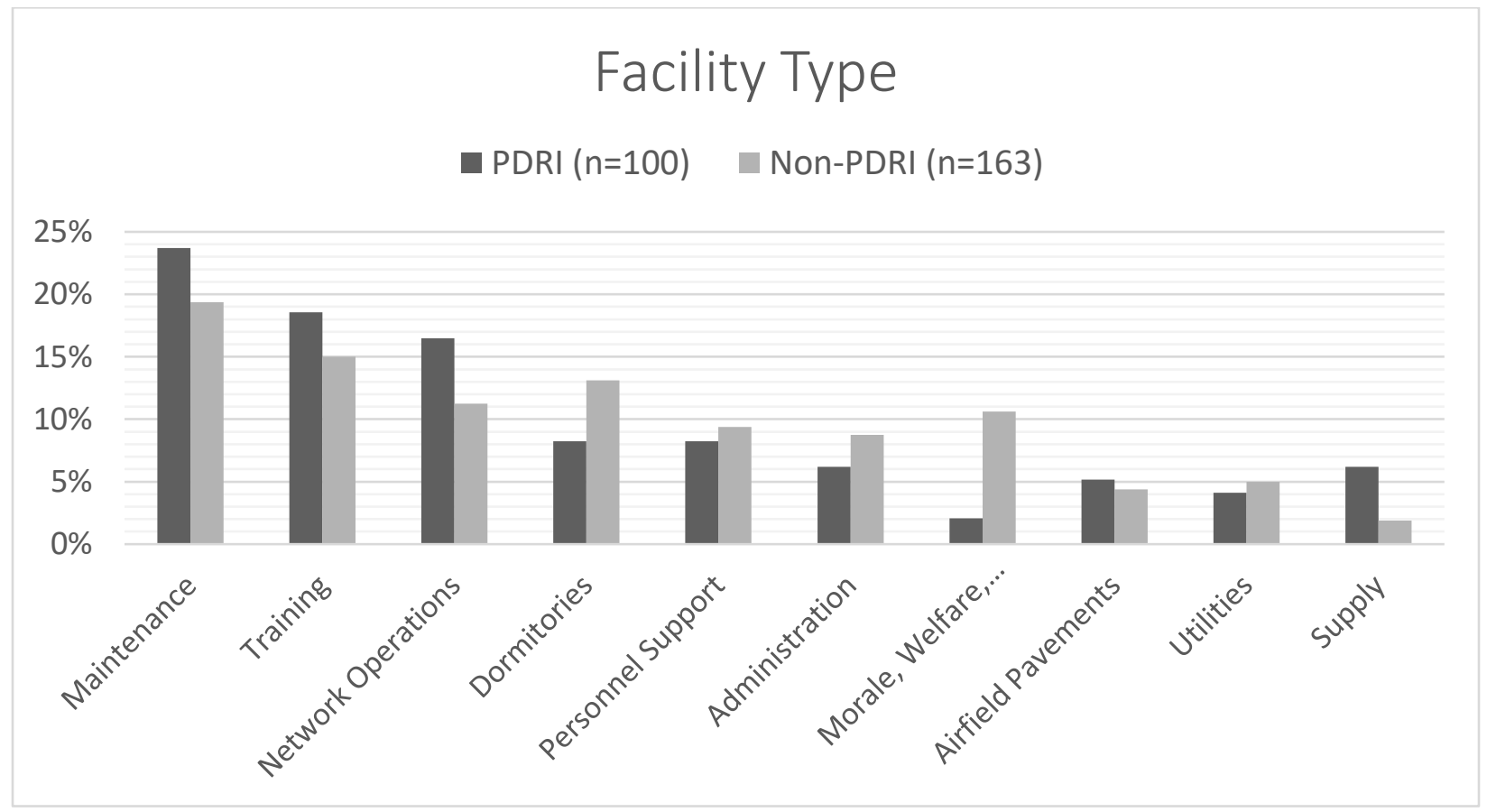

Figure 7. Project Type 
Projects that used the PDRI have a higher proportion of Airfield Pavements projects (5\% vs 4\%), a lower proportion of Personnel Support projects ( $8 \%$ vs 9\%), and a significantly lower proportion of Morale, Welfare, and Recreation projects (2\% vs 11\%, Fisher' Exact test for proportions $p=0.012$ ). By comparing the groups across these four areas, we concluded that even with the minor difference in facility type, the groups are sufficiently similar for a meaningful comparison. In other words, the similarities in these characteristics greatly reduces the effect of confounding variables on the results.

\subsection{Results}

The analysis compared the 263 projects for each of the three performance metrics- cost growth, schedule growth, and budget accuracy; Table 5 and Table 6 display the results.

Table 5. Mean Performance Results

\begin{tabular}{lcccccc} 
& \multicolumn{2}{c}{ Observations } & & \multicolumn{2}{c}{ Mean } & \\
\cline { 2 - 3 } \cline { 5 - 6 } Performance Metric & PDRI & Non-PDRI & & PDRI & Non-PDRI & p-value \\
\hline Cost Growth & 100 & 163 & & $3.5 \%$ & $5.9 \%$ & $<0.001^{*}$ \\
Schedule Growth & 100 & 163 & & $14.2 \%$ & $22.0 \%$ & $0.030^{*}$ \\
Budget Accuracy & 85 & 163 & & $15.0 \%$ & $16.5 \%$ & 0.174 \\
\hline
\end{tabular}

*Statistically significant

Table 6. Variance Performance Results

\begin{tabular}{lcccccc} 
& \multicolumn{2}{c}{ Observations } & & \multicolumn{2}{c}{ St Dev } & \\
\cline { 2 - 3 } \cline { 5 - 6 } Performance Metric & PDRI & Non-PDRI & & PDRI & Non-PDRI & p-value \\
\hline Cost Growth & 100 & 163 & & $2.9 \%$ & $5.3 \%$ & $<0.001^{*}$ \\
Schedule Growth & 100 & 163 & & $27.4 \%$ & $35.1 \%$ & $0.031^{*}$ \\
Budget Accuracy & 85 & 163 & & $11.1 \%$ & $13.3 \%$ & $0.023^{*}$ \\
\hline *Statistically significant & & & & & &
\end{tabular}

*Statistically significant

The following sections describe the results of each metric, one by one, followed by a collective discussion about their implications. 


\subsubsection{Cost Growth}

The mean cost growth for projects that implemented the PDRI was 3.5\% compared to $5.9 \%$ for projects that did not use the PDRI. The $2.4 \%$ difference between the two was highly significant with a $p$ value of less than 0.001 , leading to a rejection of the null hypothesis. This shows that projects implementing the PDRI have significantly less cost growth than projects that do not use the planning tool. Considering the current practice of assigning a 5\% contingency to all MILCON projects, this shows not only a $2.4 \%$ improvement from projects that used the PDRI, but the difference between exceeding the budget and staying in the limits; the mean cost growth of PDRI projects is under the contingency, while the mean cost growth of non-PDRI projects exceeds the contingency. Due to numerous complications associated with exceeding the approved budget, this is an important difference. These results extend and coincide with previous related work by Cho and Gibson (2001) and Wang (2002).

\subsubsection{Schedule Growth}

The mean schedule growth for PDRI projects was $14.2 \%$ while the mean for non-PDRI projects was $22.0 \%$. The $7.8 \%$ difference in schedule growth was considered significant with a $p$ value of 0.03 , leading to a rejection of the null hypothesis. Again, this shows that projects implementing the PDRI experience significantly less schedule growth than projects not using the tool. Schedule growth can be an important contributor to cost growth by way of extending equipment and overhead time on the job, but also has a less quantifiable impact on the facility user: delaying the use of the facility can have negative ramifications on productivity and morale. Similar to cost growth, this result extends previous research efforts while maintaining consistency, suggesting the benefit of increased definition on project schedule. 


\subsubsection{Budget Accuracy}

The mean budget accuracy shows the PDRI projects outperforming the non-PDRI projects for the third time. However, this result is not considered to be significant with a $p$ value of 0.174 , meaning there is approximately a $17 \%$ chance that the budget accuracy difference is purely coincidental. We fail to reject the null hypothesis. Despite the lack of significance, the $15 \%$ mean for PDRI projects against the $16.5 \%$ mean for non-PDRI projects suggests that projects using the PDRI experience slightly more accurate budget submissions. Recall that the budget accuracy is calculated from an absolute value of the difference between the budgeted amount and contracted amount, so this particular result does not show whether the projects were over- or under- budget. We analyzed the projects for differences in this area and found no statistically significant results; $14.9 \%$ of non-PDRI projects awarded a contract amount exceeding the construction budget by more than the 5\% contingency amount, compared to $16.0 \%$ of PDRI projects. These results are the first empirical comparison of budget accuracy and increased definition. Previous work has only mentioned "increased predictability of cost" due to an increased planning effort (Griffith and Gibson 2001), with no quantitative results to illustrate this point.

\subsection{Discussion}

In construction engineering and management research, it is often difficult to control project variables as the objectives, constraints, and characteristics change with each project. This study benefitted from similar data groups with one important difference: whether or not the projects in each group used the PDRI. However, the homogeneity of the groups can limit our ability to generalize findings across the industry. This section discusses the results from this 
study and compares them to other research on project scope definition to help readers put our findings into a broader context.

Projects using the PDRI statistically out-performed non-PDRI projects in two of the three analyzed metrics: cost growth and schedule growth. The PDRI variances were also significantly lower for all three metrics (Cost Growth $-2.9 \%$ vs 5.3\%, $p=0.000$; Schedule Growth $-27.4 \%$ vs $35.1 \%, p=0.031$; Budget Accuracy $-11.1 \%$ vs $13.3 \%, p=0.023)$. This shows that not only are cost and schedule growth lower on average, but there is less variation, making it easier to predict what the final cost and final schedule will be for projects that implemented the PDRI. Further, the extremes are less severe (Cost Growth - 13\% vs 23\%; Schedule Growth - 86\% vs 133\%; Budget Accuracy - 51\% vs 64\%); even when the project faces challenges, the impact on performance is lower when the PDRI is used.

Although the budget accuracy was not significantly different, both groups showed difficulty in accurately estimating the budget. This warrants further research as there are processes outside of scope definition likely affecting the ability to estimate the budget on the projects within this database.

As discussed in the background, one of the main benefits of using the PDRI is the identification of potential risks. Once the risks are identified, then a mitigation plan can be created. Moreover, the process of implementing the PDRI provides an opportunity for the entire project team to communicate and increase alignment on project objectives. Both communication and alignment have been shown to increase project performance through reduced project changes and rework, and a higher level of satisfaction among the project team and end user (Griffith and Gibson 2001). Personal communication with several Air Force managers suggest that the PDRI may not even be receiving the full benefit of the tool due to misapplication (i.e. not involving the 
entire project team, not conducting the assessment in person, and not devoting the intended efforts to identify the project's comprehensive list of risks). Despite the potential misapplication, the results indicate the value of implementing the PDRI on this set of projects.

The communication, alignment, and risk identification benefits could explain the significant difference we identified in project performance, however, the scope of this research was limited to conducting an empirical analysis that did not investigate causality. The focus was to investigate quantitative relationships, and while the results clearly show there is a difference in performance between the two groups, potential causal factors were not explored. The results do carry weight as yet another study supporting the link between the project planning effort and project performance. Furthermore, lower cost and schedule growth directly address the top performance issues of projects in the construction industry. These findings support and solidify the decision for the Air Force policy change to incorporate the use of the PDRI in project planning. Over the long term, using this tool will improve the efficiency of public expenditure, reduce construction delays, and allow better planning practices related to construction projects.

We experienced a limitation regarding both cost growth and budget accuracy calculations that rely on modification data. The database contains a separate category dedicated to tracking these modifications, providing reason codes and a brief description of the changes. The data in the modification category proved to be incomplete, as nearly half of the modifications had no reason code, and the brief description of the change was not enough to interpret the appropriate reason code. Furthermore, the current procedure for assigning reason codes is unclear and subjective; it is up to the project manager to decide whether the change is a "technical error/omission," or an "error/omission in requirement," as these are two separate codes. While the modification amounts were reliable, the lack of clarity on causes forced the authors to assume 
modifications adding to the contract price were negative as they resulted in an increase to cost growth. On the other hand, in several cases for both groups, there were reductions to the contract price resulting in a decrease to cost growth; we assumed these modifications to be positive.

Past research has shown the adaptability of military construction studies to the public sector through the consistency of results. Similarly, this research agrees with previous findings, but also extends those findings by narrowing the approach to identify the benefit of using formal scope definition tools. While the study does focus on military construction projects, the facility types, size, and delivery methods are comparable to building projects industry-wide. The combination of these factors allows these findings to fit into the broader context of the building industry as a whole. However, we caution managers about extending the application to highly specific projects, facility types outside our scope, or non-building projects.

\subsection{Conclusion}

Project scope definition is widely linked to project performance. This study examined 263 military construction projects (100 using the PDRI and 163 non-PDRI) representing \$3.9 Billion in cost to quantitatively evaluate whether there is a benefit derived from increased planning on these projects. Projects using the PDRI outperformed projects that did not in all three tested performance metrics, with significant results for cost and schedule growth, and a lack of significance for budget accuracy. This is the first study analyzing the effect of using a formal planning tool. The results are consistent with previous research on this subject that also highlight the benefits of an increased planning effort. While the study subjects are military construction projects, the results can be generalized to any organization in which the project process is streamlined and consistent. 


\subsection{Acknowledgement}

The writers appreciate the assistance received in the conducting of this research, most notably from the Air Force Civil Engineer Center, and the Air Force Institute of Technology.

\subsection{Disclaimer}

The views expressed in this article are those of the writers and do not reflect the official policy or position of the United States Air Force, Department of Defense, or United States Government.

\subsection{References}

114th Congress. (2015). National Defense Authorization Act for Fiscal Year 2016. 568-579.

Atkinson, R. (1999). "Project management: cost, time and quality, two best guesses and a phenomenon, it's time to accept other success criteria." International Journal of Project Management, 17(6), 337-342.

Atkinson, R., Crawford, L., and Ward, S. (2006). "Fundamental uncertainties in projects and the scope of project management." International Journal of Project Management, 24(8), 687-698.

Beach, M. J. (2008). “An Analysis of Cost and Schedule Performance.” Master’s Thesis, Department of Engineering Management, Air Force Institute of Technology, Wright Patterson Air Force Base, OH.

Bingham, E. (2010). "Development of the Project Definition Rating Index (PDRI) for Infrastructure Projects.” Master's Thesis, Arizona State University.

Chan, A., Ho, D., and Tam, C. (2001). "Design and Build Project Success Factors: Multivariate Analysis." Journal of Construction Engineering and Management, 127(2), 93-100. 
Chen, Q., Jin, Z., Xia, B., Wu, P., and Skitmore, M. (2015). “Time and cost performance of design-build projects.” Journal of Construction Engineering and Management, 142(2), 4015074.

Chester, M., and Hendrickson, C. (2005). "Cost Impacts, Scheduling Impacts, and the Claims Process during Construction." Journal of Construction Engineering and Management, 131(1), 102-107.

Cho, C., and Gibson, G. E. J. (2001). "Building Project Scope Definition Using Project Definition Rating Index.” Journal of Architectural Engineering, 7(4), 115-125.

Cho, C.-S., and Gibson, G. E. J. (2000a). "Development of a Project Definition Rating Index (PDRI) for General Building Projects By Chung-Suk Cho, 1 G. Edward Gibson Jr.: Members ASCE."

Cho, C.-S., and Gibson, G. E. J. (2000). “Development of a Project Definition Rating Index (PDRI) for General Building Projects.” American Society of Civil Engineers, 343-352.

Cho, K., Hong, T., and Hyun, C. (2009). "Effect of project characteristics on project performance in construction projects based on structural equation model.” Expert Systems with Applications, 36(7), 10461-10470.

Chritamara, S., Ogunlana, S. O., and Bach, N. L. (2001). "Investigating the effect of initial scope establishment on the performance of a project through system dynamics modelling." Engineering Construction \& Architectural Management (Wiley-Blackwell), 8(5/6), 381392.

Department of the Air Force. (2013). "Program Management Plan for Air Force MILCON Execution." 
Department of the Air Force. (2014). "Planning and Programming Military Construction (MILCON) Projects.” AFI 32-1021.

Dumont, P., Gibson, G. E. J., and Fish, J. (1997). "Scope Management Using Project Definition Rating Index.” Journal of Management in Engineering, 13(5), 54-60.

Fageha, M. K., and Aibinu, A. A. (2014). "Prioritising Project Scope Definition Elements in Public Building Project.” Australasian Journal of Construction Economics and Building, The, 14(3), 18.

Gibson, G. E. J., and Bosfield, R. (2012). “Common Barriers to Effective Front-End Planning of Capital Projects.” American Society of Civil Engineers, 2459-2468.

Gibson, G. E. J., Irons, K. T., and Ray, M. P. (2006a). "Front End Planning for Buildings.” American Society of Civil Engineers, 1-14.

Gibson, G. E., Wang, Y.-R., Cho, C.-S., and Pappas, M. P. (2006b). "What Is Preproject Planning, Anyway?” Journal of Management in Engineering, 22(1), 35-42.

Griffith, A. F., and Gibson, G. E. J. (2001). “Alignment during Preproject Planning.” Journal of Management in Engineering, 17(2), 69-76.

Hale, D. R., Shrestha, P. P., Gibson Jr, G. E., and Migliaccio, G. C. (2009). “Empirical comparison of design/build and design/bid/build project delivery methods." Journal of Construction Engineering and Management, 135(7), 579-587.

Kothari, C. R. (2004). Research Methodology: Methods and Techniques. New Age International. Le, T., Caldas, C. H., Gibson, G. E. J., and Thole, M. (2009). “Assessing Scope and Managing Risk in the Highway Project Development Process." Journal of Construction Engineering and Management, 135(9), 900-910. 
Mukuka, M., Aigbavboa, C., and Thwala, W. (2015). "Effects of Construction Projects Schedule Overruns: A Case of the Gauteng Province, South Africa." Procedia Manufacturing, 3, $1690-1695$.

MVP Programs. (2014). "MVPstats Help." < http://mvpprograms.com/help/mvpstats/contents> (Nov. 29, 2016).

Ramsey, F., and Schafer, D. (2012). The Statistical Sleuth: A Course in Methods of Data Analysis. Cengage Learning.

Rosenfeld, Y. (2014). "Root-Cause Analysis of Construction-Cost Overruns.” Journal of Construction Engineering and Management, 140(1), 4013039.

Rosner, J. W., Thal Jr, A. E., and West, C. J. (2009). "Analysis of the design-build delivery method in air force construction projects." Journal of Construction Engineering and Management, 135(8), 710-717.

Song, L., and AbouRizk, S. M. (2005). "Quantifying Engineering Project Scope for Productivity Modeling." Journal of Construction Engineering and Management, 131(3), 360-367.

Songer, A., and Molenaar, K. (1997). "Project Characteristics for Successful Public-Sector Design-Build.” Journal of Construction Engineering and Management, 123(1), 34-40.

Stouter, T. (2016). Cost Growth Analysis, Military Construction Programs. U.S. Army Corps of Engineers.

Thal Jr, A. E., Cook, J. J., and White III, E. D. (2010). "Estimation of Cost Contingency for Air Force Construction Projects." Journal of Construction Engineering and Management, 136(11), 1181-1188.

Wang, Y.-R. (2002). “Applying the PDRI in Project Risk Management.” PhD Thesis, Department of Civil Engineering, University of Texas at Austin, Austin, TX. 
Xia, B., Xiong, B., Skitmore, M., Wu, P., and Hu, F. (2015). "Investigating the Impact of Project Definition Clarity on Project Performance: Structural Equation Modeling Study.” Journal of Management in Engineering, 32(1), 4015022. 
Appendix A. Weighted PDRI Score Sheet

\begin{tabular}{|c|c|c|c|c|c|c|c|}
\hline \multicolumn{8}{|c|}{ SECTION I - BASIS OF PROJECT DECISION } \\
\hline \multirow{2}{*}{$\begin{array}{c}\text { CATEGORY } \\
\text { Element } \\
\end{array}$} & \multicolumn{6}{|c|}{ Definition Level } & \multirow[b]{2}{*}{ Score } \\
\hline & 0 & 1 & 2 & 3 & 4 & 5 & \\
\hline \multicolumn{8}{|l|}{ A. BUSINESS STRATEGY $($ Maximum Score $=214)$} \\
\hline A1. Building Use Requirements & 0 & 1 & 12 & 23 & 33 & 44 & \\
\hline A2. Business Justification & 0 & 1 & 8 & 14 & 21 & 27 & \\
\hline A3. Business Plan & 0 & 2 & 8 & 14 & 20 & 26 & \\
\hline A4. Economic Analysis & 0 & 2 & 6 & 11 & 16 & 21 & \\
\hline A5. Facility Requirements & 0 & 2 & 9 & 16 & 23 & 31 & \\
\hline A6. Future Expansion/Alteration Considerations & 0 & 1 & 7 & 12 & 17 & 22 & \\
\hline A7. Site Selection Considerations & 0 & 1 & 8 & 15 & 21 & 28 & \\
\hline A8. Project Objectives Statement & 0 & 1 & 4 & 8 & 11 & 15 & \\
\hline \multicolumn{7}{|c|}{ CATEGORY A TOTAL } & \\
\hline \multicolumn{8}{|l|}{ B. OWNER PHILOSOPHIES (Maximum Score $=68$ ) } \\
\hline B1. Reliability Philosophy & 0 & 1 & 5 & 10 & 14 & 18 & \\
\hline B2. Maintenance Philosophy & 0 & 1 & 5 & 9 & 12 & 16 & \\
\hline B3. Operating Philosophy & 0 & 1 & 5 & 8 & 12 & 15 & \\
\hline B4. Design Philosophy & 0 & 1 & 6 & 10 & 14 & 19 & \\
\hline \multicolumn{8}{|c|}{ CATEGORY B TOTAL } \\
\hline \multicolumn{8}{|l|}{ C. PROJECT REQUIREMENTS (Maximum Score $=131$ ) } \\
\hline C1. Value-Analysis Process & 0 & 1 & 6 & 10 & 14 & 19 & \\
\hline C2. Project Design Criteria & 0 & 1 & 7 & 13 & 18 & 24 & \\
\hline C3. Evaluation of Existing Facilities & 0 & 2 & 7 & 13 & 19 & 24 & \\
\hline C4. Scope of Work Overview & 0 & 1 & 5 & 9 & 13 & 17 & \\
\hline C5. Project Schedule & 0 & 2 & 6 & 11 & 15 & 20 & \\
\hline C6. Project Cost Estimate & 0 & 2 & 8 & 15 & 21 & 27 & \\
\hline \multicolumn{8}{|c|}{$\begin{array}{l}\text { CATEGORY C TOTAL } \\
\end{array}$} \\
\hline Section I Maximum Score $=413$ & & $\overline{\mathrm{CT}}$ & $\overline{\mathrm{ON}}$ & ITO & TAL & & \\
\hline
\end{tabular}

Definition Levels

$0=$ Not Applicable $\quad 2=$ Minor Deficiencies $\quad 4=$ Major Deficiencies

$1=$ Complete Definition $3=$ Some Deficiencies $5=$ Incomplete or Poor Definition 


\begin{tabular}{|l|l||c|c|c|c|c|c|}
\hline \multicolumn{4}{|c|}{ SECTION II - BASIS OF DESIGN } \\
\hline $\begin{array}{l}\text { CATEGORY } \\
\text { Element }\end{array}$ & \multicolumn{5}{|c|}{ Definition Level } & \\
\hline & 0 & 1 & 2 & 3 & 4 & 5 & Score \\
\hline
\end{tabular}

D. SITE INFORMATION (Maximum Score $=109$ )

D1. Site Layout

D2. Site Surveys

D3. Civil/Geotechnical Information

D4. Governing Regulatory Requirements

D5. Environmental Assessment

D6. Utility Sources with Supply Conditions

D7. Site Life Safety Considerations

D8. Special Water and Waste Treatment Req'mts

\begin{tabular}{|c||c|c|c|c|c|}
\hline 0 & 1 & 4 & 7 & 10 & 14 \\
\hline 0 & 1 & 4 & 8 & 11 & 14 \\
\hline 0 & 2 & 6 & 10 & 14 & 19 \\
\hline 0 & 1 & 4 & 8 & 11 & 14 \\
\hline 0 & 1 & 5 & 9 & 12 & 16 \\
\hline 0 & 1 & 4 & 7 & 10 & 13 \\
\hline 0 & 1 & 2 & 4 & 6 & 8 \\
\hline 0 & 1 & 3 & 6 & 8 & 11 \\
\hline
\end{tabular}

E. BUILDING PROGRAMMING (Maximum Score $=162$ )

E1. Program Statement

E2. Building Summary Space List

E3. Overall Adjacency Diagrams

E4. Stacking Diagrams

E5. Growth and Phased Development

E6. Circulation and Open Space Requirements

E7. Functional Relationship Diagrams/Rm. by Rm.

E8. Loading/Unloading/Storage Facilities Req'mts

E9. Transportation Requirements

E10. Building Finishes

E11. Room Data Sheets

E12. Furnishings, Equipment, and Built-Ins

E13. Window Treatment

\begin{tabular}{|c||c|c|c|c|c|}
\hline 0 & 1 & 5 & 9 & 12 & 16 \\
\hline 0 & 1 & 6 & 11 & 16 & 21 \\
\hline 0 & 1 & 3 & 6 & 8 & 10 \\
\hline 0 & 1 & 4 & 7 & 10 & 13 \\
\hline 0 & 1 & 5 & 8 & 12 & 15 \\
\hline 0 & 1 & 4 & 7 & 10 & 13 \\
\hline 0 & 1 & 3 & 5 & 8 & 10 \\
\hline 0 & 1 & 2 & 4 & 6 & 8 \\
\hline 0 & 1 & 3 & 5 & 7 & 9 \\
\hline 0 & 1 & 5 & 8 & 12 & 15 \\
\hline 0 & 1 & 4 & 7 & 10 & 13 \\
\hline 0 & 1 & 4 & 8 & 11 & 14 \\
\hline 0 & 0 & 2 & 3 & 4 & 5 \\
\hline
\end{tabular}

CATEGORY E TOTAL 


\begin{tabular}{|c|c|c|c|c|c|c|c|}
\hline \multicolumn{8}{|c|}{ SECTION II - BASIS OF DESIGN (continued) } \\
\hline \multirow{2}{*}{$\begin{array}{c}\text { CATEGORY } \\
\text { Element }\end{array}$} & \multicolumn{6}{|c|}{ Definition Level } & \multirow[b]{2}{*}{ Score } \\
\hline & 0 & 1 & 2 & 3 & 4 & 5 & \\
\hline \multicolumn{8}{|c|}{ F. BUILDING/PROJECT DESIGN PARAMETERS (Maximum Score = 122) } \\
\hline F1. Civil/Site Design & 0 & 1 & 4 & 7 & 11 & 14 & \\
\hline F2. Architectural Design & 0 & 1 & 7 & 12 & 17 & 22 & \\
\hline F3. Structural Design & 0 & 1 & 5 & 9 & 14 & 18 & \\
\hline F4. Mechanical Design & 0 & 2 & 6 & 11 & 15 & 20 & \\
\hline F5. Electrical Design & 0 & 1 & 5 & 8 & 12 & 15 & \\
\hline F6. Building Life Safety Requirements & 0 & 1 & 3 & 5 & 8 & 10 & \\
\hline F7. Constructability Analysis & 0 & 1 & 4 & 8 & 11 & 14 & \\
\hline \multirow[t]{2}{*}{ F8. Technological Sophistication } & 0 & 1 & 3 & 5 & 7 & 9 & \\
\hline & \multicolumn{6}{|c|}{ CATEGORY F TOTAL } & \\
\hline \multicolumn{8}{|l|}{ G. EQUIPMENT (Maximum Score $=36$ ) } \\
\hline G1. Equipment List & 0 & 1 & 5 & 8 & 12 & 15 & \\
\hline G2. Equipment Location Drawings & 0 & 1 & 3 & 5 & 8 & 10 & \\
\hline G3. Equipment Utility Requirements & 0 & 1 & 4 & 6 & 9 & 11 & \\
\hline \multicolumn{8}{|c|}{ CATEGORY G TOTAL } \\
\hline Section II Maximum Score $=429$ & \multicolumn{6}{|c|}{ SECTION II TOTAL } & \\
\hline
\end{tabular}




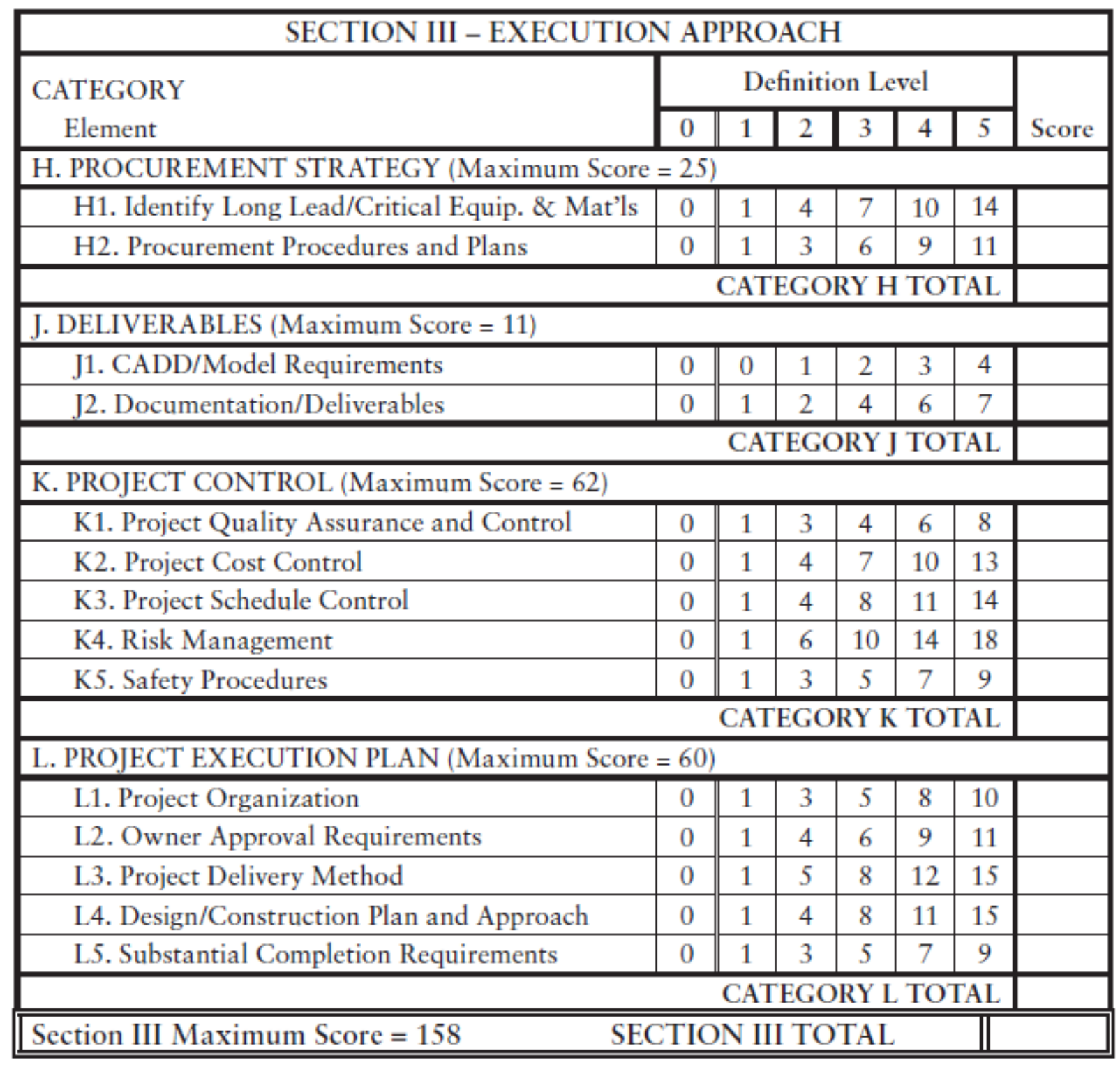

PDRI TOTAL SCORE
Maximum Score $=1000$

Definition Levels

$0=$ Not Applicable $\quad 2=$ Minor Deficiencies

1 = Complete Definition $3=$ Some Deficiencies $5=$ Incomplete or Poor Definition 


\section{Chapter 3: Conclusion}

Construction engineering and management literature points to scope definition as a leading factor of success. The construction industry has adopted tools to aid planners in developing a project scope, yet little research has been conducted to test the effectiveness of using the tool during its intended stage. Previous planning research has used the PDRI as a way to measure the level of scope definition after the project was completed. However, no previous studies have evaluated the use of the PDRI empirically. As a result, the purpose of this research was to help quantify the impact of using a formal scope definition tool on project performance. This chapter provides an overview of the research contributions as well as limitations and recommended future research.

\subsection{Contributions}

Based on the results of this study, there are several contributions, both theoretical and practical. First, the theoretical contributions include adding to the project management body of knowledge by providing an empirical analysis on the effect of using formal scope definition tools during planning. Cho and Gibson (2000) and Wang (2002) provide a detailed look at the PDRI for buildings, but their analyses were limited to post construction implementation. Cho and Gibson (2001) later observed benefits of using the tool during its intended planning stage, but were unable to study that effect empirically. This research extends those studies by not only confirming that a link between scope definition and performance exists, but providing the quantitative evaluation needed to validate the tool that was designed to help increase definition. In other words, we have known that project performance is enhanced by more thorough definition for the past two decades, but this research documents that using the PDRI is an effective tool for defining project scope. Further, this study lays the foundation for deeper 
analysis of scope definition on the PDRI specifically. Now that we have discovered a quantifiable benefit to the inclusion of this tool during planning, we can explore the limits of its application and optimal usage.

The practical contributions relate to the implementation of the PDRI itself. For the military, this has proven to be a useful tool. This study solidifies the current policy requiring use of the PDRI for MILCON projects, illustrating the benefit of doing so. Over the long term, using this tool will improve the efficiency of public expenditure, reduce construction delays, and allow better planning practices related to construction projects. Moreover, using the PDRI could be the difference between meeting the budget and exceeding the contingency amount, which requires additional funding approval. Every MILCON project should be using the PDRI. To gain the full benefit of this tool on defining the project scope and identifying areas of risk, managers should facilitate it with the entire project team during the planning phase. Finally, the results can be generalizable to other organizations for use on building projects of a similar facility type and cost range. Because the cost of implementation is minimal, large organizations with consistent project development practices can and should adopt the use of this tool.

\subsection{Limitations and Future Research}

This study is notably different from previous PDRI research in that it compares impact to performance based on whether or not the PDRI was used rather than associating the planning effort with a PDRI score, and then comparing that score to the performance. That is, it looks at the benefit of using the tool specifically, not just increased scope definition. The method of study was developed through an iterative process that experienced several limitations along the way. This changed the direction of the research from an in-depth look at PDRI scores to a broader 
examination of the tool as a whole. The following paragraphs describe the limitations and recommended future research to overcome them.

Implementation of the Building PDRI on MILCON projects has been mandatory beginning with the FY11 program, however, the consistency and diligence of application have varied greatly. As such, the number of completed projects in the US Army Corps of Engineers (USACE) database is limited. This research was limited in its ability to investigate the impact of specific PDRI scores due to the small number of available projects. An increase in the number of projects coupled with consistency of application would also decrease the amount and impact of scoring errors on projects. The result would be a large set of projects with reliable scores relating to the level of definition for each element.

The PDRI has already become a more integral part of the planning process in the last two years through changes in policy, making the assigned scores a more reliable reflection of the actual planning status, and less likely an area where the user checked a box simply because it was required. As the program develops and more projects are incorporated into this system, a more robust study with a significantly higher number of projects opens doors for several additional areas to explore: the impact of individual scope definition elements that affect performance, a stepwise regression examining the impact of multiple elements acting together, and the impact of the elements in relation to timing of implementation. These areas could improve the effectiveness of the PDRI by quantitatively evaluating the importance of each element, detailing the top elements on which to focus planning effort.

Because of the timeline for the research, I chose to study a project set for which I already had access to a large amount of data. As such, I limited the study to MILCON projects. As described in previous sections, there are numerous benefits to using this data set, most notably 
that all projects are developed under a consistent process and executed in a similar manner. However, focusing on this set of projects limits the generalizability of the findings. I've argued that based on project characteristics, the results can be applied outside the military, but the generalizability would have increased had the data set included more than just MILCON projects. The ideal set of projects would include both public and private sector organizations that could be compared against one another in addition to being studied collectively. Multiple organizations would also mean a larger set of projects to analyze, and the increase in sample size helps reduce the effect of confounding variables on the results.

Another major limitation of this study is associated with modification data. While the database has relevant modification data, it is nowhere near thorough enough to conduct a meaningful analysis. Studying the modifications could help gain insight as to why these projects suffer from cost and schedule growth, as well as link planning and PDRI scores to the modifications that make a difference. The only way to overcome this limitation is to implement procedures that will increase the quality of the data. That is, train project managers on the importance and consistency of modification data entry. Consistent application would require clear guidelines as to what reason code to apply in a given situation, and ensuring that every modification is associated with a reason code.

The initial approach of this research was to extrapolate planning data from interviews with project managers. Fortunately, I discovered the USACE database of PDRI scores and no longer needed the interview data, because it was extremely difficult to track down the right person or group of people involved in the planning process of the selected projects. Often, the contact information for the project would lead to the member who inherited the project for closeout, and either did not know who was involved in planning, or the planning team had since 
relocated or retired. This can be attributed to multiple organizational alignment changes beginning in 2008. Now that the Air Force has seemingly finalized the hierarchy and development process, it is likely that better project files and planning information will be kept for future research.

Finally, this research focused on evaluating relationships rather than investigating causality. This limitation was again due to the research timeline. Now that the relationships have been discovered and we know they are statistically significant, future research can engage with project management staff to discover why these relationships exist. A better understanding of the causal effect between using the PDRI and project performance could allow enhanced application and a more efficient use of resources while still achieving positive outcomes. To accomplish that goal, the researchers would need to take a more qualitative approach. Analyzing the data by itself limits the researcher to identifying relationships rather than explaining them. The qualitative approach could include a synthesis of existing literature with expert interviews, then validating the findings through an additional survey. Additionally, a case study approach would be appropriate to add depth and gain insight to the quality of application and perceived benefits from users.

\subsection{Final Thoughts}

This process has been enlightening. Perhaps the most significant takeaway was discovering the importance of the iterative process. Throughout the first several months of the research, I was narrowly focused on the outcome I intended to achieve. This led to a narrowly focused literature review, methodology development, and low level of flexibility in terms of findings. As I continued to make discoveries, the direction of the study changed slightly, and I realized I needed to broaden the approach. I am extremely satisfied with the final results. Only in 
the last month or so did I actually realize the distinctiveness of my research, and the resulting implications. After immersing myself with project planning and the PDRI specifically, I think the tool should be used, at least in some version, on just about every project. The benefits of thorough planning and risk identification far outweigh the low cost of a two-to-four hour meeting. This is a low-risk, high-reward situation for project teams, and can go a long way to minimizing the amount of wasted resources in the construction industry. 


\section{Bibliography}

114th Congress. (2015). National Defense Authorization Act for Fiscal Year 2016. 568-579.

Atkinson, R. (1999). "Project management: cost, time and quality, two best guesses and a phenomenon, it's time to accept other success criteria." International Journal of Project Management, 17(6), 337-342.

Atkinson, R., Crawford, L., and Ward, S. (2006). "Fundamental uncertainties in projects and the scope of project management." International Journal of Project Management, 24(8), $687-698$.

Beach, M. J. (2008). “An Analysis of Cost and Schedule Performance.” Master’s Thesis, Department of Engineering Management, Air Force Institute of Technology, Wright Patterson Air Force Base, OH.

Bingham, E. (2010). "Development of the Project Definition Rating Index (PDRI) for Infrastructure Projects.” Master's Thesis, Arizona State University.

Chan, A., Ho, D., and Tam, C. (2001). "Design and Build Project Success Factors: Multivariate Analysis." Journal of Construction Engineering and Management, 127(2), 93-100.

Chen, Q., Jin, Z., Xia, B., Wu, P., and Skitmore, M. (2015). “Time and cost performance of design-build projects." Journal of Construction Engineering and Management, 142(2), 4015074.

Chester, M., and Hendrickson, C. (2005). "Cost Impacts, Scheduling Impacts, and the Claims Process during Construction.” Journal of Construction Engineering and Management, 131(1), 102-107.

Cho, C., and Gibson, G. E. J. (2001). "Building Project Scope Definition Using Project Definition Rating Index.” Journal of Architectural Engineering, 7(4), 115-125. 
Cho, C.-S., and Gibson, G. E. J. (2000a). "Development of a Project Definition Rating Index (PDRI) for General Building Projects By Chung-Suk Cho, 1 G. Edward Gibson Jr.: Members ASCE."

Cho, C.-S., and Gibson, G. E. J. (2000). "Development of a Project Definition Rating Index (PDRI) for General Building Projects.” American Society of Civil Engineers, 343-352.

Cho, K., Hong, T., and Hyun, C. (2009). "Effect of project characteristics on project performance in construction projects based on structural equation model.” Expert Systems with Applications, 36(7), 10461-10470.

Chritamara, S., Ogunlana, S. O., and Bach, N. L. (2001). "Investigating the effect of initial scope establishment on the performance of a project through system dynamics modelling." Engineering Construction \& Architectural Management (Wiley-Blackwell), 8(5/6), 381392.

Department of the Air Force. (2013). "Program Management Plan for Air Force MILCON Execution."

Department of the Air Force. (2014). "Planning and Programming Military Construction (MILCON) Projects.” AFI 32-1021.

Dumont, P., Gibson, G. E. J., and Fish, J. (1997). "Scope Management Using Project Definition Rating Index.” Journal of Management in Engineering, 13(5), 54-60.

Fageha, M. K., and Aibinu, A. A. (2014). "Prioritising Project Scope Definition Elements in Public Building Project.” Australasian Journal of Construction Economics and Building, The, 14(3), 18.

Gibson, G. E. J., and Bosfield, R. (2012). “Common Barriers to Effective Front-End Planning of Capital Projects.” American Society of Civil Engineers, 2459-2468. 
Gibson, G. E. J., Irons, K. T., and Ray, M. P. (2006a). “Front End Planning for Buildings.” American Society of Civil Engineers, 1-14.

Gibson, G. E., Wang, Y.-R., Cho, C.-S., and Pappas, M. P. (2006b). "What Is Preproject Planning, Anyway?" Journal of Management in Engineering, 22(1), 35-42.

Griffith, A. F., and Gibson, G. E. J. (2001). “Alignment during Preproject Planning.” Journal of Management in Engineering, 17(2), 69-76.

Hale, D. R., Shrestha, P. P., Gibson Jr, G. E., and Migliaccio, G. C. (2009). “Empirical comparison of design/build and design/bid/build project delivery methods." Journal of Construction Engineering and Management, 135(7), 579-587.

Kothari, C. R. (2004). Research Methodology: Methods and Techniques. New Age International.

Le, T., Caldas, C. H., Gibson, G. E. J., and Thole, M. (2009). “Assessing Scope and Managing Risk in the Highway Project Development Process." Journal of Construction Engineering and Management, 135(9), 900-910.

Mukuka, M., Aigbavboa, C., and Thwala, W. (2015). "Effects of Construction Projects Schedule Overruns: A Case of the Gauteng Province, South Africa.” Procedia Manufacturing, 3, $1690-1695$.

MVP Programs. (2014). "MVPstats Help.”<http://mvpprograms.com/help/mvpstats/contents> (Nov. 29, 2016).

Ramsey, F., and Schafer, D. (2012). The Statistical Sleuth: A Course in Methods of Data Analysis. Cengage Learning.

Rosenfeld, Y. (2014). “Root-Cause Analysis of Construction-Cost Overruns.” Journal of Construction Engineering and Management, 140(1), 4013039. 
Rosner, J. W., Thal Jr, A. E., and West, C. J. (2009). “Analysis of the design-build delivery method in air force construction projects.” Journal of Construction Engineering and Management, 135(8), 710-717.

Song, L., and AbouRizk, S. M. (2005). “Quantifying Engineering Project Scope for Productivity Modeling." Journal of Construction Engineering and Management, 131(3), 360-367.

Songer, A., and Molenaar, K. (1997). "Project Characteristics for Successful Public-Sector Design-Build." Journal of Construction Engineering and Management, 123(1), 34-40.

Stouter, T. (2016). Cost Growth Analysis, Military Construction Programs. U.S. Army Corps of Engineers.

Thal Jr, A. E., Cook, J. J., and White III, E. D. (2010). "Estimation of Cost Contingency for Air Force Construction Projects." Journal of Construction Engineering and Management, 136(11), 1181-1188.

Wang, Y.-R. (2002). “Applying the PDRI in Project Risk Management.” PhD Thesis, Department of Civil Engineering, University of Texas at Austin, Austin, TX.

Xia, B., Xiong, B., Skitmore, M., Wu, P., and Hu, F. (2015). "Investigating the Impact of Project Definition Clarity on Project Performance: Structural Equation Modeling Study.” Journal of Management in Engineering, 32(1), 4015022. 